


\section{AN OPTIMUM START/STOP CONTROL ALGORITHM FOR HEATING AND COOLING SYSTEMS IN BUILDINGS}

Cheol Park

U.S. DEPARTMENT OF COMMERCE

National Bureau of Standards

National Engineering Laboratory

Center for Building Technology

Washington, DC 20234

May 1983

Sponsored by:

Office of Building and Community Systems

U.S. Department of Energy

U.S. Navy Civil Engineering Laboratory

U.S. Department of Defense

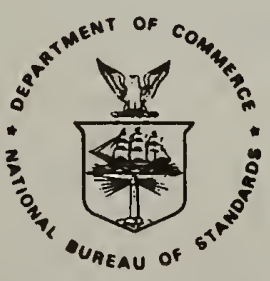

U.S. DEPARTMENT OF COMMERCE, Malcolm Baldrige, Secretary NATIONAL BUREAU OF STANDARDS, Ernest Ambler, Director 


\section{ABSTRACT}

When a building structure is occupied intermittently, energy savings can be realized from the optimal start-up and shut-down of the heating or cooling system. This strategy, known as optimum start/stop control, reduces energy consumption by delaying the start-up of the space conditioning system until the last moment and then initiating shut-down as early as possible, while maintaining a preset level of comfort during the period of building occupancy.

Based on the bang-bang control theory, a simple optimum start/stop control algorithm is developed for computerized control systems in buildings. The optimum start time is obtained by finding the intersection of cool-down and heat-up curves that are approximated by exponential fitting of the previous and current day's data.

Information is presented in this report on the input and output variables, logic flow, and methodology employed in developing the algorithm. A computer program listing of the optimum start/stop control algorithm written in FORTRAN 77 and sample input and output data are included in the appendices.

Key words: digital control systems; energy conservation; energy management and control systems; heating and cooling systems; optimum start/stop time; preheat time. 


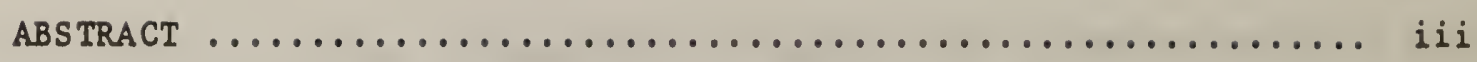

LIST OF FIGURES $\ldots \ldots \ldots \ldots \ldots \ldots \ldots \ldots \ldots \ldots \ldots \ldots \ldots \ldots \ldots \ldots \ldots \ldots \ldots \ldots$

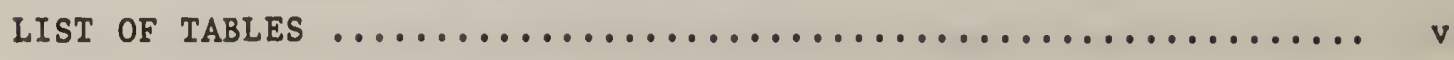

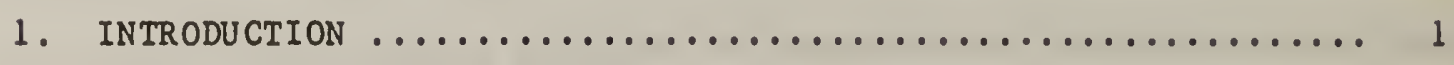

2. OPTIMUM START/STOP ALGORITHM $\ldots \ldots \ldots \ldots \ldots \ldots \ldots \ldots \ldots \ldots$

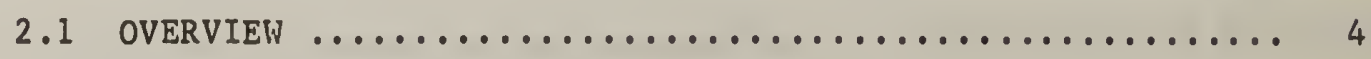

2.2 INPUT AND OUTPUT DATA $\ldots \ldots \ldots \ldots \ldots \ldots \ldots \ldots \ldots \ldots \ldots$

2.3 ASSUNPTIONS AND LIMITATIONS $\ldots \ldots \ldots \ldots \ldots \ldots \ldots \ldots \ldots, 8$

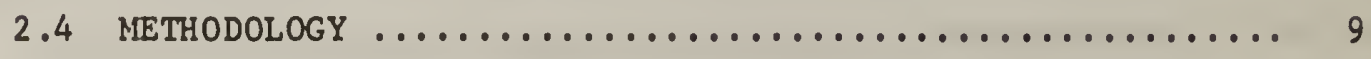

2.5 APPLICATION NOTES $\ldots \ldots \ldots \ldots \ldots \ldots \ldots \ldots \ldots \ldots \ldots \ldots \ldots \ldots \ldots \ldots \ldots \ldots \ldots$

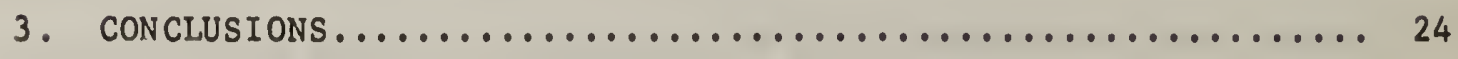

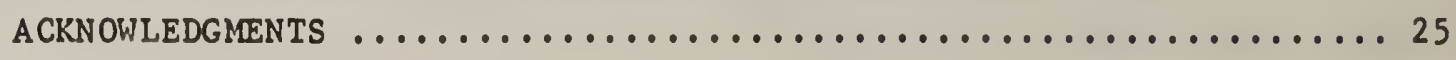

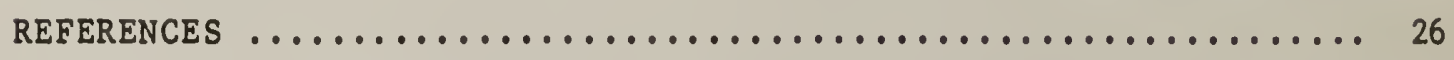

APPENDIX A. DETERMINATION OF OPTIMUM START TIME FOR HEATING $\ldots . .27$

APPENDIX B. FLOW CHARTS OF THE COMPUTER PROGRAMS $\ldots \ldots \ldots \ldots \ldots 34$

APPENDIX C. COMPUTER PROGRAM LISTING ............... 41

APPENDIX D. SAMPLE INPUT AND OUTPUT OF THE PROGRAM $\ldots \ldots \ldots \ldots .53$ 


\section{LIST OF FIGURES}

$\underline{\text { Page }}$

Figure 1. Room air temperature with respect to time of day under an ideal situation $\ldots \ldots \ldots \ldots \ldots \ldots \ldots \ldots \ldots$

Figure 2. Room air temperature with respect of time of day under a realistic situation $\ldots \ldots \ldots \ldots \ldots \ldots \ldots \ldots$

Figure 3. A case with the on-off control operation ........ 12

Figure 4. A typical temperature history during the initial cycle $\ldots \ldots \ldots \ldots \ldots \ldots \ldots \ldots \ldots \ldots \ldots \ldots \ldots \ldots$

Figure 5. Relationships of subprograms ................ 14

Figure 6 . Flow chart of the main algorithm, optss ........ 16

\section{LIST OF TABLES}

Table 1. Cross reference table of notation 


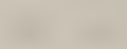




\section{INTRODUCTION}

When a building is occupied intermittently, energy savings can be realized by minimizing the time the heating or cooling system is operated. The interior building temperature is maintained at a comfortable level only during occupancy. For example, during the heating season, the heating system is turned off shortly before the end of an occupied period and the space temperature decays until the heating equipment is reactivated. This reactivation occurs either because a new occupied period is approaching or because the indoor temperature has reached a predetermined minimum temperature which must be maintained to prevent freezing and condensation problems. Building control algorithms that try to determine the start and stop times for the heating and cooling equipment such that start-up is delayed until the last moment and shut-down takes place as early as possible before the end of occupancy, are commonly referred to as "optimum start/stop" algorithms [1,2]. One such algorithm is the subject of this report.

Due to thermal inertia of both the building structure and its heating and cooling equipment, a preheat or precool time is almost always required to raise or lower the space temperature to the desired level before the beginning of occupancy. This start-up time depends on the outdoor environment, the thermal response of the building envelope, and the thermal performance of space conditioning equipment [3-5]. The starting time of the equipment is the main value to be determined in optimum start control. Optimum stop control makes use of the dead time after the heating or cooling equipment is turned off when thermal inertia prevents the indoor temperature from dropping below 
or rising above confort levels. This sllows the system to be turned off before the end of an occupied period.

Practical use of opti=ue start control was accomplished by Jackson $[3,4]$ on a heating system using an analog control device. With an intuitively derived relationship between indoor and outdoor air temperatures, the start time of preheat period was deterained. Jackson claimed substantial energy savings Izo the use of optimu start control. He also indicated that a nighttime setback teciniçue ws not econonically justified in control of intermittently occupied buildings. A Eield study was made by Eenderson [5] comparing optimum start control with nighttine setback. Bloomfield and Fisk [6] described the optinization of intermittent heating with a detailed mathematical presentation and wade sizulations using prior knowledge of the thernal response factors of building structures.

Using recursive least squares estialion, a self-tuning optimum start control algorith= for a heating plant was developed by Dexter [7]. The preheat start tine is expressed in terms of bulk structure teaperature and unknown parameters that aze to be determined acaptively using daily data. Both analog and digital simulations were made. The estimate of bulk temperature was calculated using a first order difference equation with a bulk time constant representing the thermal behavior of the structure.

As microprocessors became available, the HVAC industry began to implement =icrocozputers to control building equipzent. Although software developed by industry exists on the market, details of the algorithms are not generally available in the public domain. The purpose of this report is to introduce a 
simple optimum start/stop algorithm which bs been developed fordigital control of heating systems. With minimal changes, the same algorithm can be used to optimally start and stop building cooling systems.

In the algorithm presented, the starting time for the heating system is determined by using both the temperature rise characteristics during the preheat period of the previous day and the temperature decay behavior during the current cool-down period. The stop time is determined from the delay in the temperature cool-down cycle. A provision for prevention of freezing and condensation problems is also incorporated. The nature of the algorith used is adaptive, but the approach is much simpler than that used by Dexter [7]. Neither a time series analysis nor recursive least squares estiration is involved. 


\section{OPTIMUM START/STOP ALGORITHM}

\subsection{OVERVIEW}

According to optimum control theory, minimization of energy use can be achieved if the control is of the "bang-bang" type [8]. This means that, in the heating mode, the heating system operates at full power during the preheat period and at zero power during the cool-down period. Similar operating procedures are applied in the cooling mode, but for simplicity only heating operation will be described in detail. In addition, it will be assumed that the minimum temperature reached during the off-period is greater than the space temperature which would result in freezing or condensation problem.

The bang-bang control scheme is applied only during the unoccupied period. If the outdoor environmental conditions remain constant during the unoccupied period, an ideal situation is illustrated as shown in figure 1. Room air temperature, $T_{R A}$, responds immediately on the starting or stopping of the heating equipment. Thermal inertia of the building structure or of the heating system is not accounted for. This kind of ideal response is impossible in the real world. Figure 2 represents a more realistic response. The outdoor environment and thermal response characteristics of the building structure determine the length of the preheat period.

In the optimum start/stop algorithm presented in this report, the start time for heating is determined by using the temperature rise characteristics during the heat-up period of the previous day and the temperature decay characteristics during the current cool-down period. The stop time is determined from the delay in the temperature decay. 


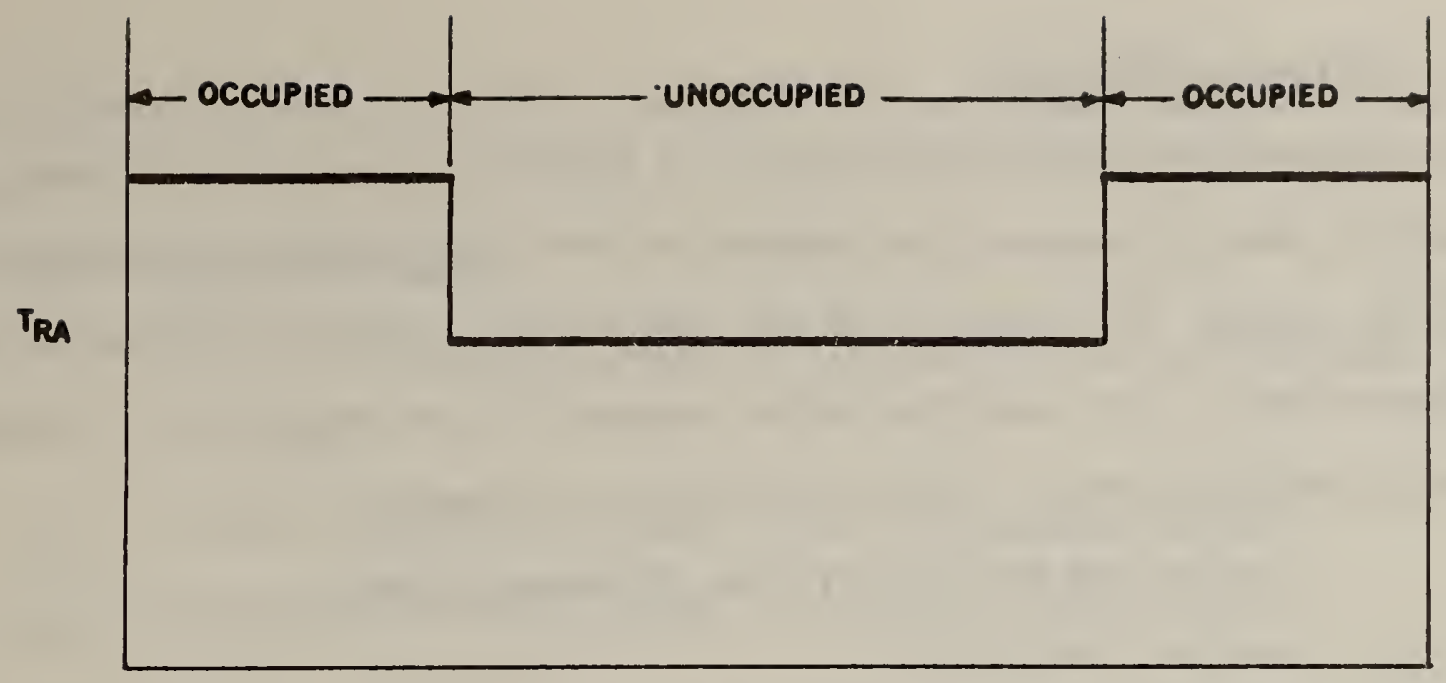

TIME OF DAY

Figure 1. Room air temperature with respect to time of day under an ideal situation

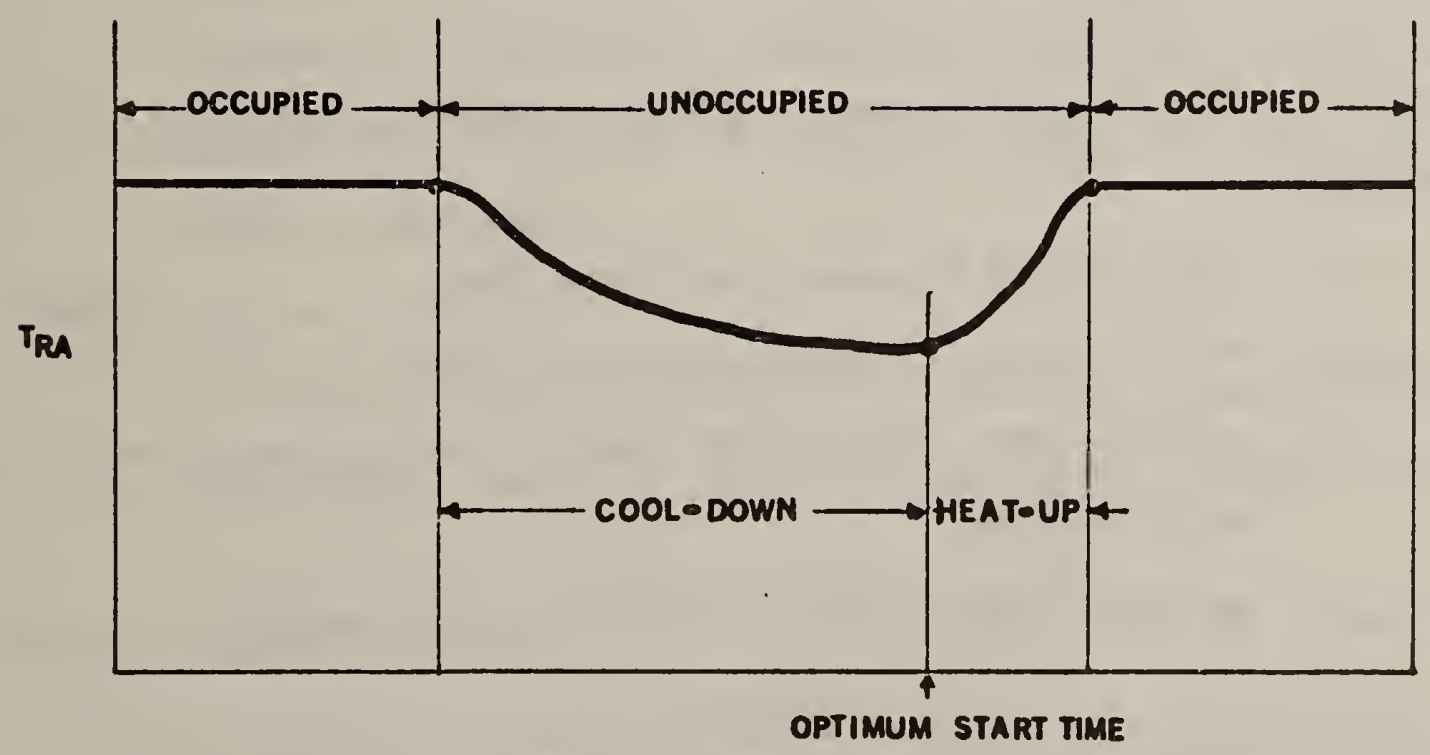

TIME OF DAY

Figure 2. Room air temperature with respect to time of day under a realistic situation 


\subsection{INPUT AND OUTPUT DATA}

It is assumed that the optimum start/stop algorithm is not executed continuously, but at discrete time intervals. The time interval is called the sampling period. The sampling period used depends upon the building response characteristics. The sampling period assigned in this report is 15 minutes. At each sampling instant, the following data are sampled:

$t$ : time of day in military time expressed in hours

$\mathrm{T}_{\mathrm{RA}}$ : room air temperature

$\mathrm{T}_{\mathrm{OA}}$ : outdoor air dry-bulb temperature

Units for temperature data can be either metric or English units. Instead of room air and outdoor air temperatures, interior and exterior surface temperatures of a building structure may be used. Surface temperature measurements usually contain less noisy and more stable signals.

As initial input data, the main algorithm (OPTSS) requires the following information:

$t_{\text {occ }}$ : start time of occupancy (military time)

$t_{\text {unoc: }}$ ending time of occupancy (military time)

$t_{s}$ : initial guess of starting time for use in the learning cycle (military time)

$y_{\text {set }}$ : set point temperature during the occupied period

In addition, the room air temperature must be maintained above a minimum temperature to prevent freezing and condensation problems during the heating season, and it should not be higher than a maximum temperature during the 
cooling season. Because of this, the following additional input data are also needed:

HEAT: logical variable

For the heating mode, HEAT is true and for the cooling mode, HEAT is false.

$y_{\min }$ : minimum temperature allowed during the heating season

$y_{\max }$ : maximum temperature allowed during the cooling season

While the most important output is the start time, $t_{\delta}$, the following logical outputs are also provided for the purpose of system control via supporting software and hardware:

DAYCNT: logical variable

If DAYCNT is true, the daytime controller is to be called, otherwise the daytime controller is not called. The daytime controller is referred as a controller to be used in maintaining $y_{\text {set }}$ during the occupied period assuming that the occupied period is at daytime.

FSYSON: logical variable

If FSYSON is true, the heating (or cooling) system operates at full output. Otherwise the heating (or cooling) system operates at less than full output.

MAINTN: logical variable

If MAINTN is true, a controller is called to maintain a minimum requirement in heating (or cooling). 
When a simple on-off controller is used to maintain the minimum unoccupied temperature during the heating mode (or the maximum permissible temperature level during the cooling mode). Information on the on-off temperature differential, $\Delta y$, will also be required.

\subsection{ASSUMPTIONS AND LIMITATION}

The following assumptions were made in the development of the optimum start/stop algorithm:

(a) Full output operation is carried out only by the heating equipment during the preheating period and by the cooling equipment during the precooling period.

(b) A daytime controller (e.g., PI-controller) is available during the occupied period and both the daytime control and the optimum start/stop control do not interfere with each other in their operations. If the occupancy period is at nighttime, the daytime controller should be considered as a nighttime controller.

(c) Execution of the algorithm is performed once every sampling period of 15 minutes (i.e., four samples per hour).

(d) Maintaining a minimum (maximum) temperature load in the heating (cooling) mode during the off-period is done by an on-off controller.

The use of the algorithm in an actual implementation is not limited as long as the computer used in the controls associated with the system to be controlled has enough capacity to store sampled data and the program. 


\subsection{METHODOLOGY}

The optimum start time for heating is determined by using a measured temperature rise curve from the preheat period of the previous day and a measured temperature decay curve from the current cool-down period, and finding the intersecting point of the two curves before occupancy. Equations of the two curves are approximated by simple exponential fits based on actual data. Each equation contains a single time constant $(\tau)$, and one predetermined time $\left(x_{i}\right)$ with its corresponding measured temperature $\left(y_{i}\right)$. Each time constant is determined from the exponential fitted equation using two data points. The intersection of two curves are obtained using a method for finding a root of the function which is expressed as a difference of two fitted equations.

An $x-y$ coordinate system is employed to express these equations for convenience. Time and temperature are denoted by $x$ and $y$, respectively, and the origin of the $x$-axis is chosen as a midpoint of the occupied period. When the occupancy schedule for the next cycle (e.g., next day) is changed (i.e., $t_{o c c}$ and $t_{\text {unoc }}$ are varied) before the beginning of the occupied period, the origin of the $x$-axis is translated by the amount of the change made.

Although it is desirable that the space temperature reaches the target temperature (set point) at the beginning of occupancy, the desired temperature may not be reached on time due to approximation errors in curve fitting and/or changes in characteristics of heating (cooling) equipment and building thermal response from the previous day's state. The temperature will reach the set point a little earlier or later than the optimum time. The fitted temperature rise curve is thus corrected by the amount of time offset, $x_{0}$. 
When the building thermal response is slow and the heating or cooling system has a transport delay (dead time), then the space temperature does not rise immediately, but responds after a certain time period is passed. The time period without the response of temperature rise may be called the "flat response" period or simply system dead time, don' Under these circumstances, the start time obtained by finding two curves should be advanced by the amount of the system dead time. Details on how the start time, $x_{s}$, for heating mode is determined can be found in Appendix A, where mathematical expressions are provided.

At the beginning of the unoccupied period, the heating system is usually turned off. However, when the decay of indoor temperature is slowed by the thermal characteristics of the building structure, energy savings can be realized by advancing the turning-off of the heating system so that the "flat response" period is included in the occupied period. This advanced stop time will be referred to as the optimum stop time, even though its determination is not based on optimum control theory. This approach is simple, compared with the method developed by Bloomfield and Fisk [6].

When the outdoor air temperature is low enough, the indoor air temperature may fall below the desired minimum temperature, $y_{m i n}$, during the off-period. The indoor temperature must be maintained above the minimum temperature to prevent freezing and condensation problems. A simple on-off control may be utilized to maintain the minimum level of temperature. The heating system is turned on when $y \leq y_{m i n}$, and turned off when $y \geq y_{m i n}+\Delta y$. In this case, the full capacity operation of the heating system may not be necessary, and partial 
load operation may be adequate. This is illustrated in figure 3 , where the dead time is assumed to be zero.

A typical temperature history during the initial cycle (learning cycle) is illustrated in figure 4. Possible time delays and offset are included.

Assuming the program run starts at near a midpoint time of the occupied period of a typical weekday in the heating season, the following is a simplified description of the sequence of operations performed by the program:

(1) Get initial input data and set initial conditions.

(2) Start to take data of $t, T_{R A}\left(=y_{4}\right)$, and $T_{0 A}$ every 15 minutes.

(3) Turn off the system at the beginning of the unoccupied period.

(4) Determine dead time during the off-period.

(5) Check if on-off control is necessary to maintain a minimum space temperature ( $y \leq y_{\min }$ any time during the off-period).

(6) Turn on the system at the given initial guess of the start time.

(7) Determine dead time during the on-period.

(8) Turn off the system at the beginning of occupancy and let a daytime controller take over.

(9) Update constant values, $x_{1}, x_{2}, x_{3}, y_{1}, y_{2}$, and $y_{3}$ (see Appendix A for definition).

(10) Determine the minimum outdoor temperature.

(11) Update the heat-up curve.

(12) Determine the interval where an intersecting point of the heat-up and cool-down curves locates.

(13) Begin a new cycle at the midpoint of the following day's occupied period. 


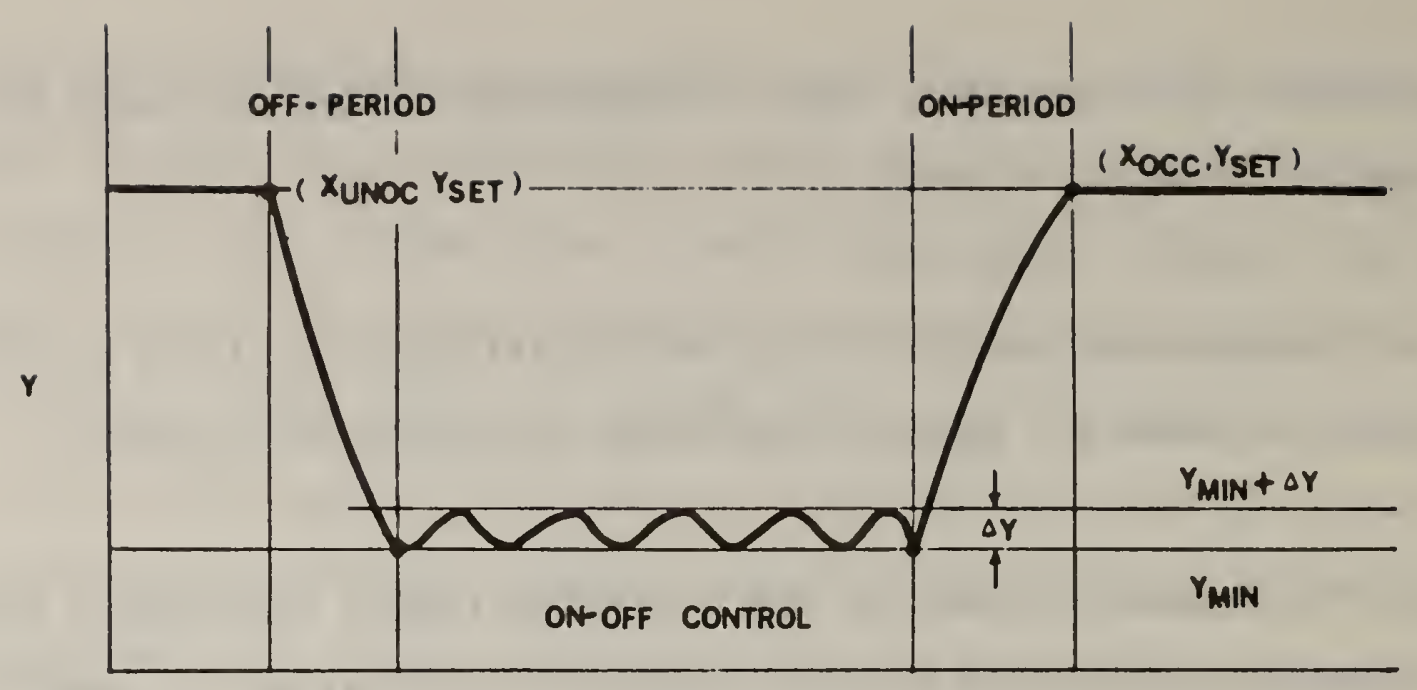

$x$

Figure 3. A case with the on-off control operation

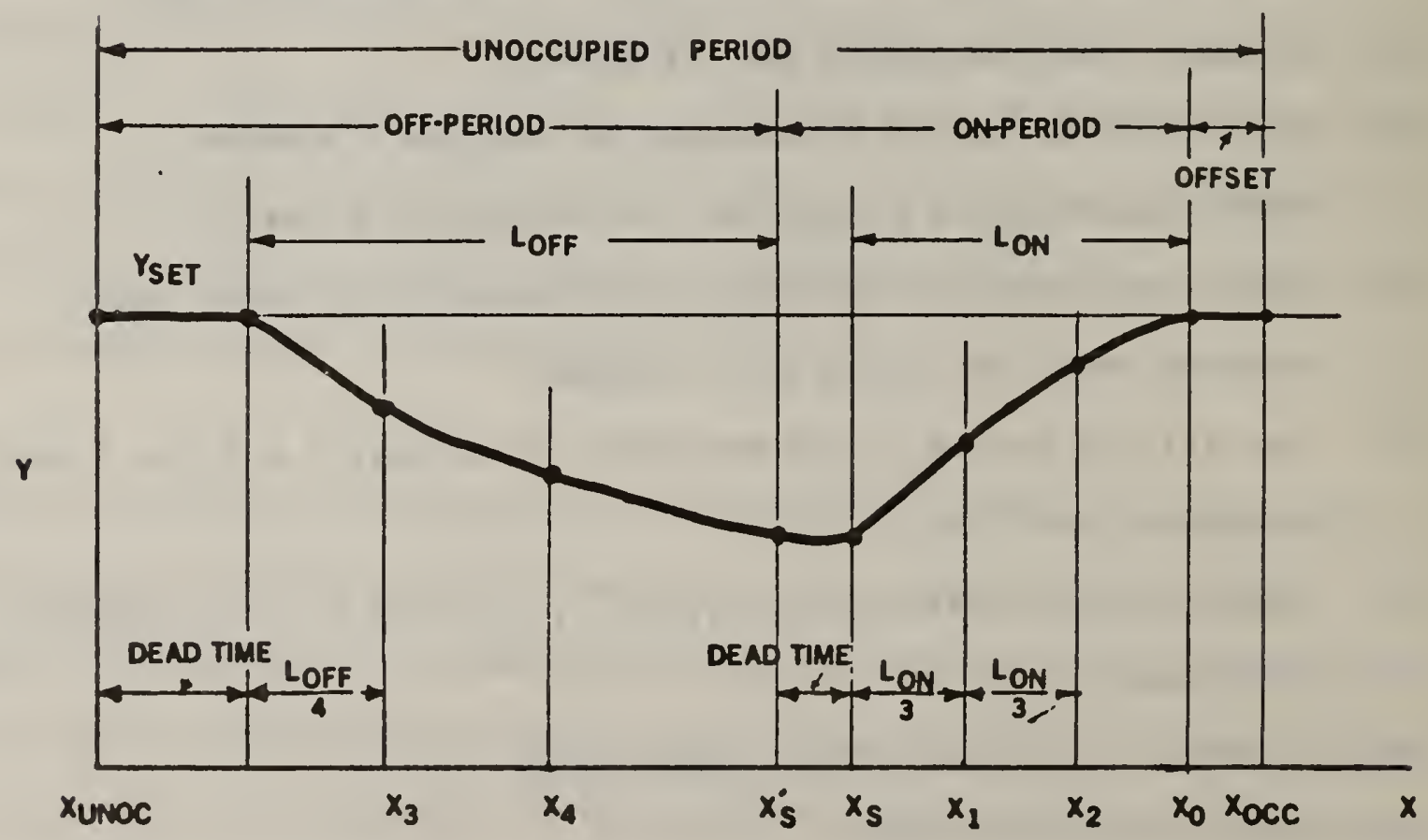

Figure 4. A typical temperature history during the initial cycle 
(14) Turn off the system before the beginning of the unoccupied period by the amount equal to the off-period dead time.

(15) Repeat steps (4) through (5).

(16) Find the intersection of the heat-up and cool-down temperature curves by using the regula falsi method (false position method) [9].

(17) Predict the new start time incorporating the on-period dead time determined previously.

(18) Turn on the system at the newly calculated start time.

(19) Go to step (7).

It is possible to generalize the optimum start/stop control algorithm from the heating mode to the cooling mode by relaxing some of the assumptions made in Appendix A. The same equations used for heating given in Appendix A can be used for cooling except that $y$ is taken to be the highest outdoor dry-bulb temperature during the unoccupied period, the value of $\mathrm{y}_{\mathrm{SS}}$ is approximated as $0.5 \mathrm{y}_{\text {set }}$ and the maximum allowable space temperature, $y_{\mathrm{max}}$, replaces $y_{\mathrm{min}}$ whenever it appears.

Figure 5 shows a block diagram of the relationships between procedures in the main algorithm. The following are brief descriptions of each routine shown in this figure:

OPTSS: Primary routine for optimum start/stop control. Each event is controlled sequentially. Both heating and cooling season operations are included.

XITRT: Left-most and right-most values of the time coordinate ( $x$ ) are computed to be used as upper and lower limits of the interval in 


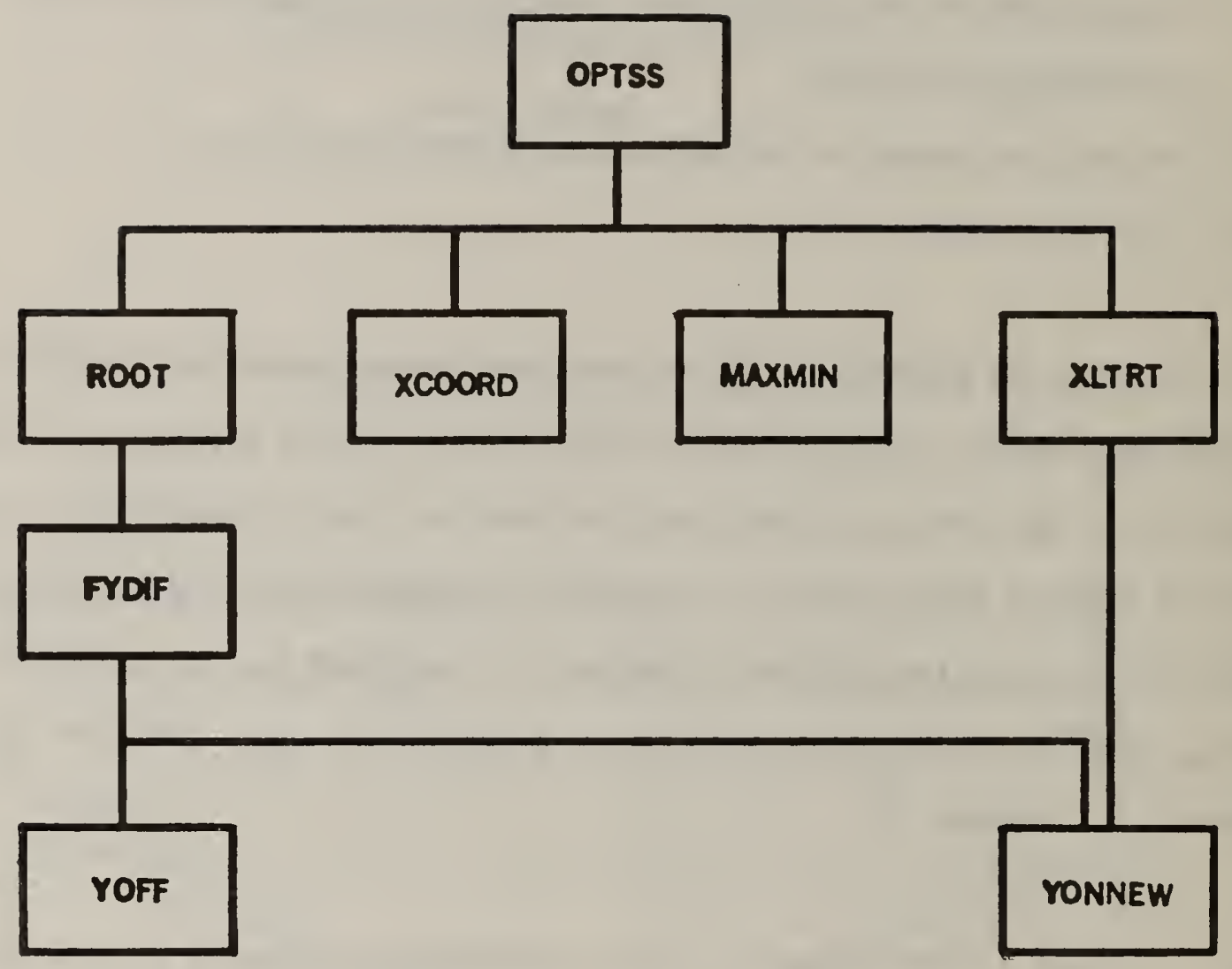

Figure 5. Relationships of subprograms 
ROOT subroutine.

ROOT: This subroutine finds the real root of a function in a given interval.

MAXMIN: A subroutine to obtain the maximum and minimum values of a given array.

XCOORD: This subroutine converts military time into the modifed time coordinate, $x$, and vice versa.

FYDIF: A function that obtains the difference of two functional values.

YONNEW: A function to update the heat-up profile, $y_{O N}(x)$. (See Appendix A.) .

YOFF: A function to describe the building cool-down profile, $y_{O F}(x)$. (See Appendix A.)

The flow chart of the main algorithm, the subroutine OPTSS, is shown in figure 6. Further detailed flow charts of the OPTSS and the associate subprograms are given in Appendix B. Table 1 is a cross reference of the notation used in the computer program, flow charts, main text, and Appendix A. A complete listing of the computer program appears in Appendix C. The computer progran was written in FORTRAN 77 for the UNIVAC $1100 / 82$ computer.

\subsection{APPLICATION NOTES}

The subroutine OPTSS contains four COMMON blocks of shared storage space with other subroutines and the main program. The DATA statements in the OPTSS contain the following pre-assigned numerical data:

EPS: small positive real number specifying the accuracy required of the ROOT routine $(=0.005)$. 


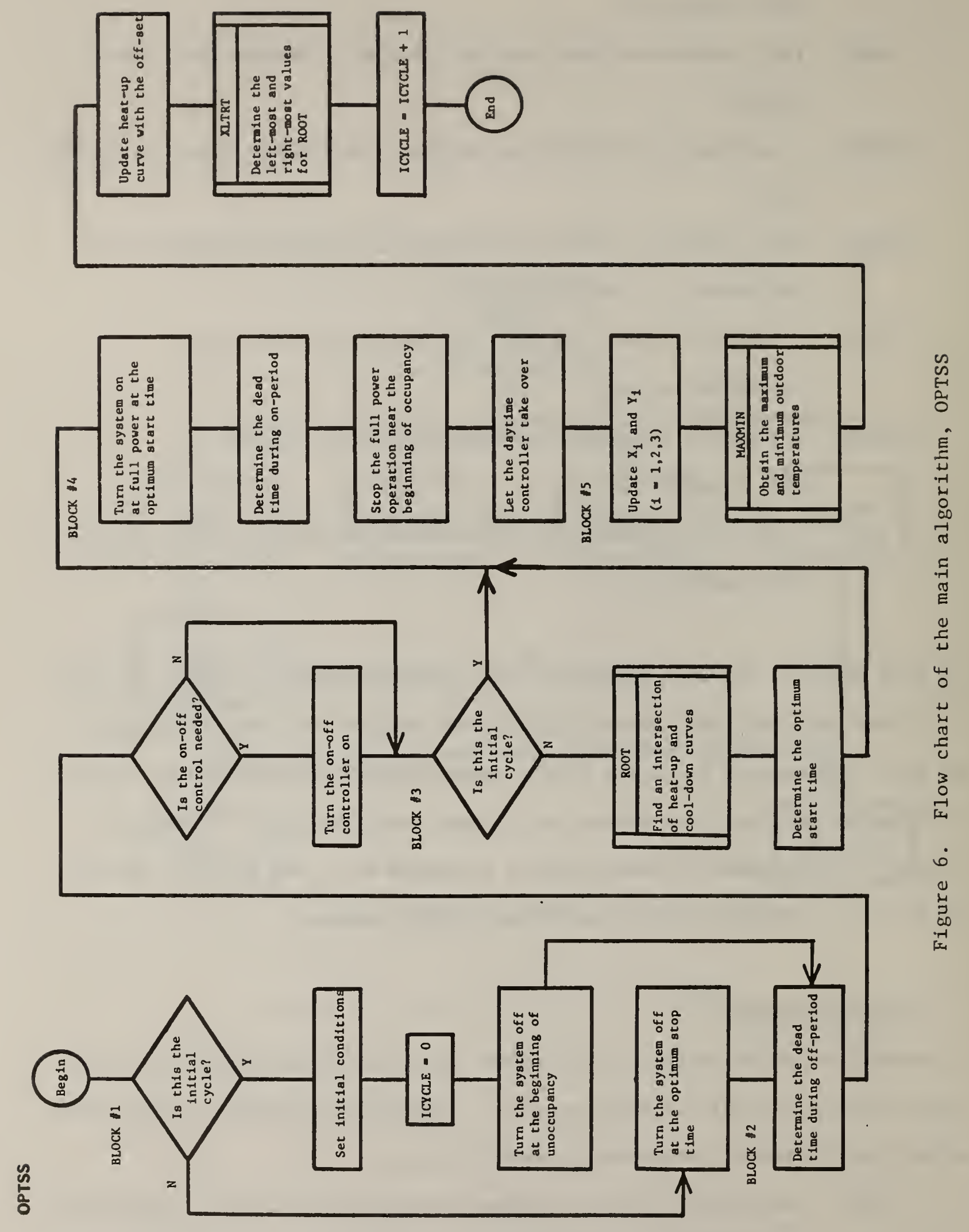


Table 1. Cross reference table of notation

Notation

in Programs

$A(I)$

AMAX

AMIN

DATE

DAY

DAYCNT

DELY

DX

EPS

EPSOFF

EPSON

EPSSET

EPSX

FSYSON

FX

FXL

FXR

FX2

\section{Descriptions}

array values

maximum value of array values

minimum value of array values

date

0 for non-working day

1 for working day

true if the daytime controller operates

false if the daytime controller does not operate

temperature difference

time increment used in XLTRT

positive small number for accuracy used in ROOT

positive sma11 number

positive small number

positive small number

positive small number determined

by sampling frequency

true if the system operates at full FSYSON power

false if the system is off

scalar function values

functional value of $\mathrm{FX}$ with the argument of $\mathrm{XL}$

functional value of $F X$ with the argument of $\mathrm{XR}$

Intermediate value of FX $f(x)$

Notation Notation in Flow Charts in the Text

$A(I)$

AMAX

AMIN

DATE

DAY

DAYCNT

DAYCNT

$\Delta \mathrm{Y}$

$\Delta \mathrm{y}$

$\Delta \mathrm{X}$

$\varepsilon$

FSYSON

$\mathrm{f}_{\mathrm{L}}$

$\mathrm{f}_{\mathrm{R}}$

$f^{\prime}$ 
Notation

in Programs

HEAT

ICYCLE

IEND

IFLAG

ISTART

ITDOWN

ITER

ITIME

ITMAX

ITOFF

ITON

ITSET

ITUNOC

ITUP

IW

MAINTN

\section{Description}

true if heating mode

false if cooling mode

number of cycles (e.g., one cycle per day)

Index number of ending of search

0 if finding a root is successful

1 if finding a root is not successful

Index number of beginning of search

Index number where temperature

decay begins

number of 1teration

Index number of modifled time of day

maximum number of 1teration to obtain a root

Index number where $\mathrm{X}=\mathrm{XOFF}$

Index number where $\mathrm{X}=\mathrm{XSTART}$

index number where temperature reaches at set point

Index number where $\mathrm{X}=\mathrm{XUNOC}$

index number where temperature rise begins

index to control printing out

true if the on-off control is needed

false if the on-off control is not needed
Notation Notation

in Flow Charts in the Text

HEAT

HEAT

IEND

IFLAG

ISTART

ITDOQN

I

IMAX

ITOFF

ITON

ITSET

ITUNOC

ITUP

MAINTN

MAINTN 
Notation

in Programs

$\mathrm{N}$

NMAX

NPTHR

NSKIP

PARTON

RSCHDL

SWI

TAUOFF

TAUON

TBEGIN

TDEDOF

TDEDON

TEMP

TIME

TIMEX

TITLE

TOA (I)

\section{Description}

number of intervals used in XLTRT

total number of samples a day

number of samples in one hour

number of records to be skipped

true if the system operates with

a partial capacity

false if the system is off

time when the schedule file is

read (military time)

event control switches

$(I=0, \ldots, 7)$

system time constant during

off-period

system time constant during on-period

origin of $\mathrm{x}$-axis (military time)

dead time during off-period

dead time during on-period

indoor or internal surface

temperature

time of day (military time)

modified time of day in scalar

title of input data set in two

rows

outdoor temperature
Notation

in Flow Charts in the Text

PARTON

SWi

${ }^{\tau}$ OFF $\quad \tau_{\text {OFF }}$

$\tau_{\text {ON }} \tau_{\text {ON }}$

$t_{B}$

$\mathrm{d}_{\mathrm{OFF}}$

$\mathrm{d}_{\mathrm{ON}}$

$\mathrm{d}_{\mathrm{ON}}$

$\mathrm{T}_{\text {RA }}$

TIME

t

$\mathrm{T}_{\mathrm{OA}}(\mathrm{I}) \quad \mathrm{T}_{\mathrm{OA}}$ 
Notation

in Programs

TOCC

TOFF

TOUT

TSTART

TUNOC

XD

XDATA (I)

XL

XOCC

$\mathrm{xOCCl}$

XOFF

$\mathrm{XR}$

XROOT

XSTART

XUNOC

XUNOC1

$\mathrm{XX}$

$X(I)$

\section{Description}

beginning time of occupancy

(military time)

optimum stop time (military time)

dry-bulb outdoor temperature

optimum start time (military time)

beginning time of unoccupancy

(military time)

$\mathrm{X}$-value where $\mathrm{Y}$-value is equal to YSET

modified time of day (X-value)

left-most value of $\mathrm{X}$

beginning of occupancy

past value of XOCC

optimum off time

right-most value of $\mathrm{X}$

root

optimum start time

beginning of unoccupancy

past value of XUNOC

intermediate value of $\mathrm{X}$

specific time of day with its

origin TBEGIN ( $I=1,2,3,4)$
Notation Notation

in Flow Charts in the Text tocc

$t_{s}$

$t_{\text {unoc }}$

$\mathrm{x}$ o

$\mathrm{x}_{\mathrm{o}}$

$\mathrm{X}(\mathrm{I})$

$\mathrm{x}$

$\mathrm{X}_{\mathrm{L}}$

${ }^{\mathrm{x}} \mathrm{L}$

$\mathrm{x}_{\mathrm{OCC}}$

$\mathrm{x}_{\text {occ }}$

$\mathrm{X}_{\text {OFF }}$

$\mathrm{X}_{\mathrm{R}}$

$\mathrm{X}_{\mathrm{ROOT}}$

$\mathrm{X}_{\mathrm{S}}$

$\mathrm{x}_{\mathrm{S}}$

$\mathrm{X}_{\text {UNOC }}$

$x_{\text {unoc }}$

$\mathrm{XX}$

$x_{i}$

$\mathrm{x}_{\mathrm{i}}$ 
Table 1 (cont.)

Notation

in Programs

$\mathrm{X} 2$

$\operatorname{YDATA}(\mathrm{I})$

YINF

YMAX

YMIN

YOFF

YONNEW

YSET

YSS

$\mathrm{Y}(\mathrm{I})$

\section{Descriptions}

intermediate value used in ROOT

temperature (Y-value)

steady-state temperature as $\mathrm{X}$ goes to infinity during of $f$-period

maximum temperature

minimum temperature

temperature curve during cool-down period

updated temperature curve during on-period

set point temperature (target temperature)

steady-state temperature as $\mathrm{X}$ goes to infinity during on-period

temperature $(I=1,2,3,4)$
Notation Notation

in Flow Charts in the Text

$X^{\prime}$

$Y(I)$

y

$Y_{\infty}$

$y_{\infty}$

$\mathrm{Y}_{\mathrm{MAX}}$

$\mathrm{y}_{\max }$

$\mathrm{Y}_{\mathrm{MIN}}$

$\mathrm{y}_{\text {min }}$

$\mathrm{Y}_{\mathrm{OFF}}$

$\mathrm{y}_{\mathrm{OFF}}(\mathrm{X})$

$\mathrm{Y}_{\mathrm{ON}}$

$\mathrm{y}_{\mathrm{ON}}(\mathrm{X})$

$\mathrm{Y}_{\text {SET }}$

$y_{\text {set }}$

$\mathrm{Y}_{\text {SS }}$

$\mathrm{y}_{\mathrm{SS}}$

$Y_{i}$

$\mathrm{y}_{i}$ 
ITMAX: maximum number of iterations permitted in ROOT to obtain a root within the specified accuracy $(=20)$

EPSOFF: small positive real number for the temperature tolerance used in determining the dead time during the off-period $\left(=0.25^{\circ} \mathrm{C}\right)$

EPSON: small positive real number for the temperature tolerance used in determining the dead time during the on-period $\left(=0.25^{\circ} \mathrm{C}\right)$

EPSSET: small positive real number for the temperature tolerance used in reaching the daytime set point temperature $\left(=0.25^{\circ} \mathrm{C}\right)$

The above numerical values were assigned to be appropriate for the simulated system under control. Depending upon the characteristics of the building and the heating/cooling system, the values in the DATA statements may be changed accordingly.

For testing purposes, the main program, OPMAIN, can be used. This program, which is listed at the end of Appendix C, calls the main routine, OPTSS, and the on-off control routine, ONOFF. In the OPMAIN program, the on-off control routine is the only routine called during non-working days. The on-off controller may be replaced with another type controller if desired. If occupancy schedule changes are needed, new values of $t_{o c c}$ and $t_{\text {unoc }}$ for the next cycle must be provided before the ending of the current cycle.

A simulation run of the program has been made using a predetermined temperature history of the outdoor air and the room air to demonstrate input-output operation. Input data and resulting output data of this run are presented in Appendix D, and may be used for test purposes. 
If the sampling frequency is to be changed, the integer number NPTHR in the PARAMETER statement of the OPTSS and OPMAIN routines must be changed. For example, if the sampling interval is 10 minutes, the sampling frequency (NPTHR) will be 6 (samples per hour).

Implementation of the optimum start/stop control algorithm on an actual building control computer requires that the main program, OPMAIN, is to be converted into a subroutine which serves as an interface routine between the main routine, OPTSS, and a supervisory program. The supervisory program may govern data collection and transmission activity and perform high level operations; for example, choosing a proper algorithm for a given situation based on the level of priority. 


\section{CONCLUSIONS}

An optimum start/stop control algorithm is described for use in on-line digital control of HVAC systems. The start time for a heating system is determined using the temperature rise profile from the previous day's heat-up period and the temperature decay profile from the current cool-down period, and finding the point (time before occupancy) at which they intersect. The profiles are approximated from actual data using a simple exponential fit. With minor modifications, the algorithm is also capable of finding the optimum start and stop times for a building cooling system. If this algorithm is applied to lightweight, intermittently occupied buildings with low thermal inertia, energy savings should be realized, although the exact magnitude of these savings has not yet been determined. Future research involves implementation, testing, and verification of this algorithm on an energy management and control system in an actual building. 


\section{ACKN OWLEDGEMENTS}

The author is indebted to Dr. George E. Kelly and Mr. William B. May for their helpful suggestions. 


\section{REFERENCES}

1. Shih, J.Y., "Energy Conservation and Building Automation," ASHRAE Trans., Vo1. 81 , Part 1, 1975, pp. 419-435.

2. Liptak, B.G., 'Reducing the Operating Costs of Buildings by the Use of Computers," ASHRAE Trans., Vo1. 83, Part 1, 1977, pp. 343-360.

3. Jackson, T.B., 'The Theory and Economics of Optimum Start Programming of Heating Plant," J.I.H.V.E., Vo1. 39, May 1971 , pp. A24-A38.

4. Jackson, T.B., "Optimum Start Control - Why Now?," B.S.E., Vo1. 44, October 1976, pp. A24-A44.

5. Henderson, P.E., "Optimum Start Control: Principle and Practice," Energy World, February 1975, pp. 3-6.

6. Bloomfield, D.P. and Fisk, D.J., "The Optimization of Intermittent Heating," (CP 14/77) Practical Studies from the Building Research Establishment, Vol. 4, Energy Heating and Thermal Comfort, the Construction Press, Lancaster, England, pp. 101-113.

7. Dexter, A.L., "Self-turning Optimum Start Control of Heating Plant," Automatica, Vo1. 17, No. 3, 1981, pp. 483-492.

8. Sage, A.P. and White, C.C., Optimum Systems Control, 2nd Ed. PrenticeHall, 1977 .

9. Carnahan, B., Luther, H.A., and Wilkes, J.0., Applied Numerical Methods, John Wiley, 1969. 
If measured data are available on the building interior space temperature with respect to time, approximate equations can be constructed to fit both the temperature decay and rise curves that result from turning the heating equipment off and on. Assuming that the structure is very light (fast thermal response) and that the heating equipment has no dead time (immediate response), a temperature history similar to the one shown in figure A-1 may be assumed. The off- and on-periods are defined as the period when heating equipment is off and full on, respectively. For convenience, an $x-y$ coordinate system described in section 2.4 is used. Time and temperature are denoted by $x$ and $y$, respectively. Military time at the origin of the $x-y$ coordinate system is taken as a midpoint time of the occupied period.

During the on-period, an approximate equation yields:

$$
y_{O N}(x)=y_{S S}-\left(y_{S S}-y_{1}\right) e^{-\left(\frac{x-x_{1}}{\tau_{O N}}\right)}
$$

where

$$
\begin{aligned}
x_{1}= & \text { an arbitrary point of } x \text { in the on-period (the chosen value of } x_{1} \\
& \text { is one-third of the on-period plus } x \text {-value at the intersection), } \\
y_{1}= & \text { measured temperature at } x_{1}, \\
y_{S S}= & \text { steady-state temperature as } x \rightarrow \infty \text {, and } \\
\tau_{O N}= & \text { time constant during the on-period. }
\end{aligned}
$$




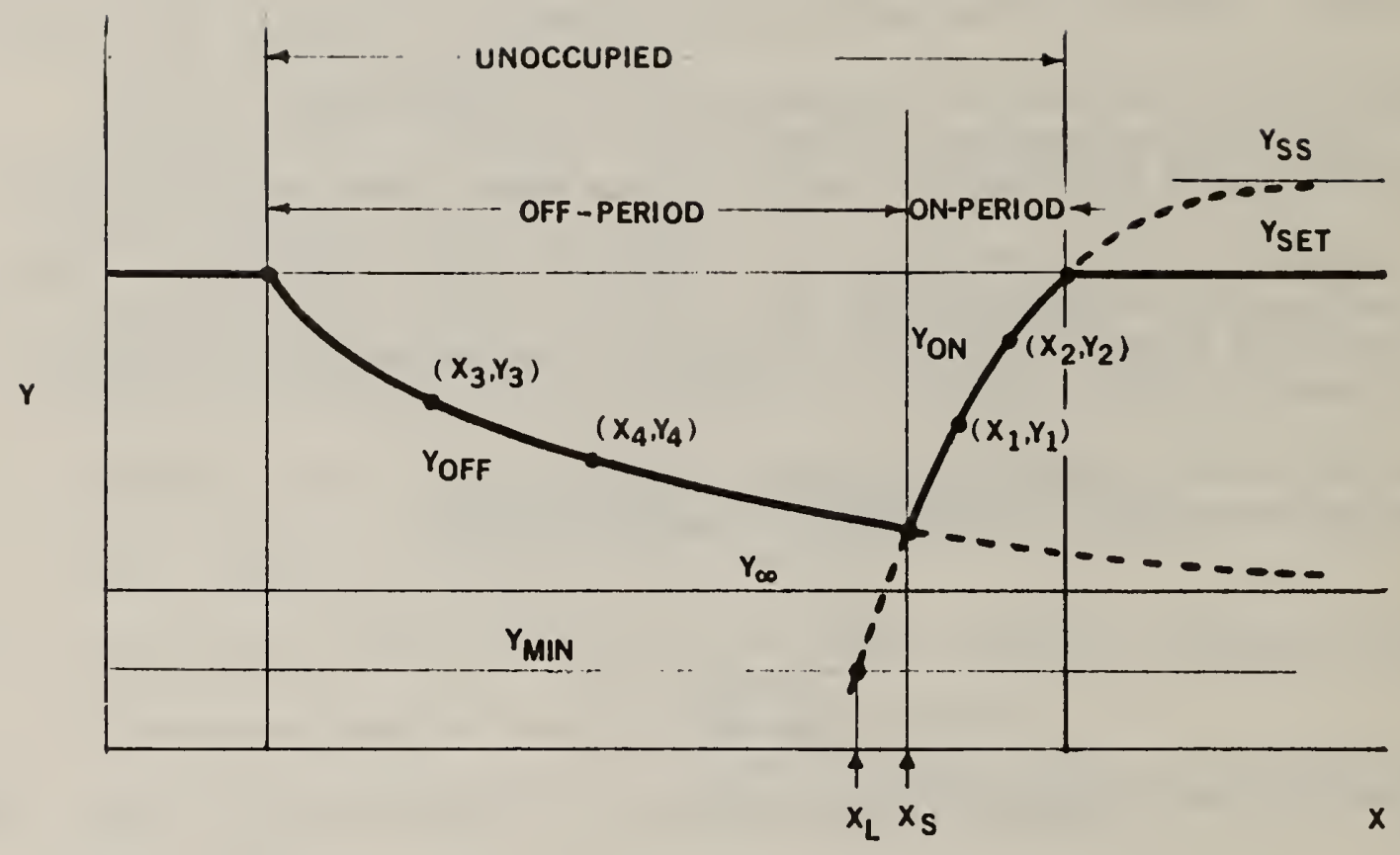

Figure A-1. Temperature history of a lightweight structure with immediate response of heating equipment 
Using two data points, $\left(x_{1}, y_{1}\right)$ and $\left(x_{2}, y_{2}\right)$, the time constant can be obtalned from:

$$
\text { ON }=\frac{x_{2}-x_{1}}{\ln \left(\frac{y_{S S}-y_{1}}{y_{S S}-y_{2}}\right)}
$$

where

$$
\begin{aligned}
x_{2}= & \text { an arbitrary point of } x \text { in the on-period which is greater than } \\
& x_{1} \text { (the chosen value of } x_{2} \text { is two-thirds of the on-period plus } \\
& x \text {-value at the intersection), and } \\
y_{2}= & \text { measured temperature at } x_{2} .
\end{aligned}
$$

An expression for the off-period is:

$$
y_{O F F}(x)=y_{\infty}+\left(Y_{3}-y_{\infty}\right) e^{-\left(\frac{x-x_{3}}{\tau_{O F F}}\right)}
$$

where

$$
\begin{aligned}
x_{3}= & \text { an arbitrary point of } x \text { in the off-period (the chosen value of } \\
& x_{3} \text { is one-fourth of the off-period plus } x \text {-value at the beginning of } \\
& \text { the unoccupied period.), } \\
y_{3}= & \text { measured temperature at } x_{3}, \\
y_{\infty}= & \text { steady-state temperature as } x \rightarrow \infty \text {, and } \\
{ }^{T} \text { OFF }= & \text { time constant during off-period. }
\end{aligned}
$$

The off-period time constant is given by

$$
\tau_{O F F}=\frac{x_{4}-x_{3}}{\ln \left(\frac{y_{3}-y_{\infty}}{y_{4}-y_{\infty}}\right)}
$$


If $y_{\infty}$ and $y_{S S}$ are predetermined, the decay and rise temperature curves can be determined using the given data points $\left(x_{1}, y_{1}\right),\left(x_{2}, y_{2}\right),\left(x_{3}, y_{3}\right)$, and $\left(x_{4}\right.$, $y_{4}$ ). The value of $y_{\infty}$ is taken to be the lowest allowable indoor dry-bulb temperature during the unoccupied period (heating mode) and $\mathrm{y}_{\mathrm{SS}}$ is approximated as $1.5 \mathrm{y}_{\text {set }}$, where $\mathrm{y}_{\text {set }}$ is the set point temperature for occupancy. Since the time domain of interest is finite, the effect on $\mathrm{y}_{\mathrm{ON}}(\mathrm{x})$ and $\mathrm{y}_{\mathrm{OFF}}(\mathrm{x})$ of errors in the estimated asymtotic values $y_{\infty}$ and $y_{S S}$ is small.

After the functions $y_{O N}(x)$ and $y_{O F F}(x)$ are determined, the point of their intersection can be obtained using a method for finding a root of a function $f(x)$, where $f(x)=y_{O N}(x)-y_{O F F}(x)$. The method used was the regula falsi method (false position method [9]). For this method, if a function is bounded and has only one root in a given interval, the solution converges within a given tolerance after a number of iterations. The time corresponding to their intersection is then considered to be the optimum start time.

Difficulties can arise in using the regula falsi method with $\mathrm{y}_{\mathrm{ON}}(\mathrm{x})$ if the whole unoccupied period is taken as the interval of interest. As seen in figure $A-1, y_{O N}(x)$ is not, in general, bounded in that interval. Thus, the left-most value, $x_{L}$, of the interval should be selected so that $y_{O N}(x)$ is bounded in that interval. The approach used in this algorithm for choosing $x_{L}$ is to set $x_{L}$ equal to the value of $x$ which satisfies the condition: $\mathrm{y}_{\mathrm{ON}}(\mathrm{x})=\mathrm{y}_{\mathrm{min}}$, where $\mathrm{y}_{\mathrm{min}}$ is the minimum temperature to maintain.

The optimum start time is determined by finding an intersection of the current temperature decay curve and the temperature rise curve of the previous day. Any changes in the heating system characteristics and environment in the 
current day could result in a change in the temperature rise curve during the current on-period.

It is desirable that the temperature rise curve reaches the target temperature (set point) at the beginning of occupancy. If the temperature rise curve changes during the on-period and there are errors due to approximation, the space temperature will reach the set point a little earlier or later than the optimum time. In order to correct this offset, the fitted temperature rise equation should be corrected by the amount of time offset.

Figure A-2 shows both the fitted curve (solid line) based on measurement and the updated curve (dotted line) during the on-period. The $x$-coordinate is shifted by the difference, $x_{o c c}-x_{0} \cdot x_{o c c}$ is the beginning of occupancy and $x_{0}$ is the point where $y$ is equal to the set point, $y_{\text {set }}$. The updated equation is then

$$
y_{\text {on }}(x)=y_{S S}-\left(y_{S S}-y_{1}\right) e^{-\left(\frac{x-x^{-}}{O N}\right)}
$$

where

$$
\begin{aligned}
& x_{1}^{\prime}=\text { the updated } x_{1} \text {, given by } \\
& x_{1}^{\prime}=x_{1}+\left(x_{\text {occ }}-x_{0}\right)
\end{aligned}
$$

and

$$
x_{0}=x_{1}-\tau_{O N} \ln \left(\frac{y_{S S}-y_{s e t}}{y_{S S}-y_{1}}\right)
$$




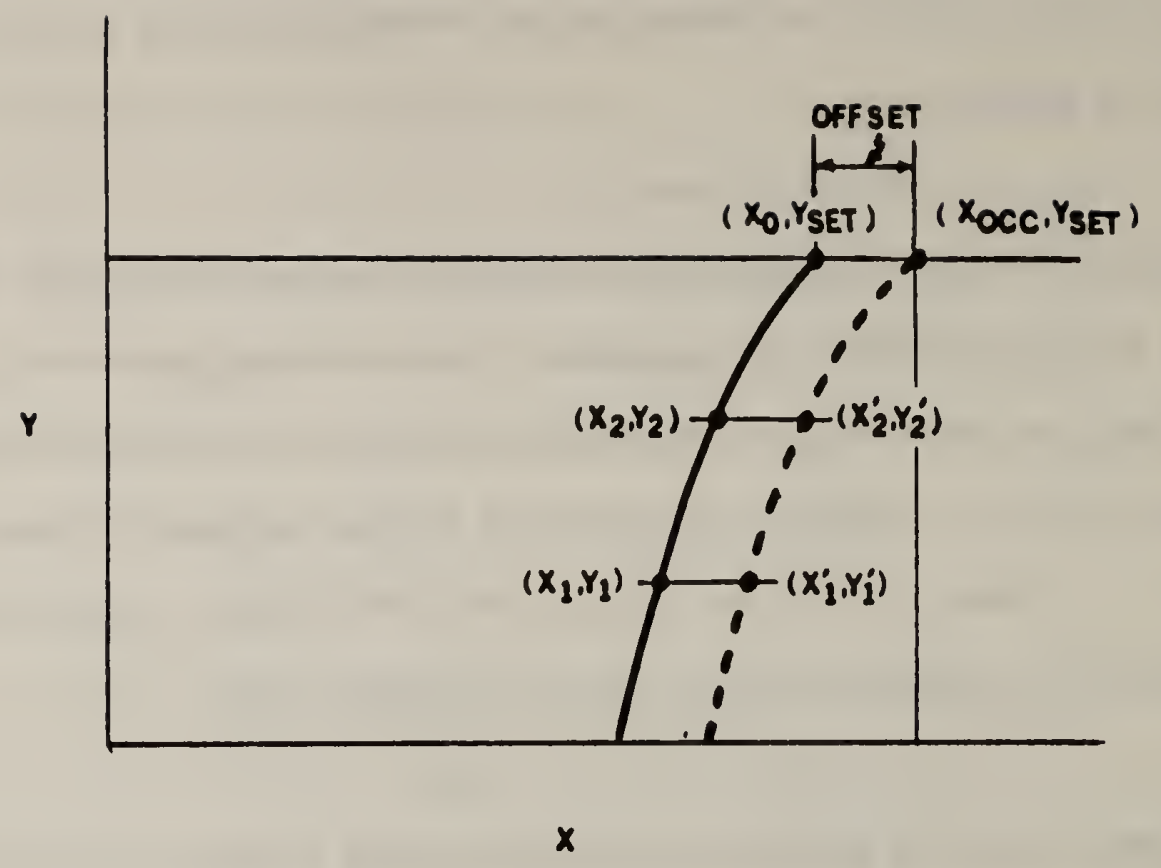

Figure A-2. The f1tted curve (solid 11ne) based on measurement and the updated curve (dotted line) during the on-per1od

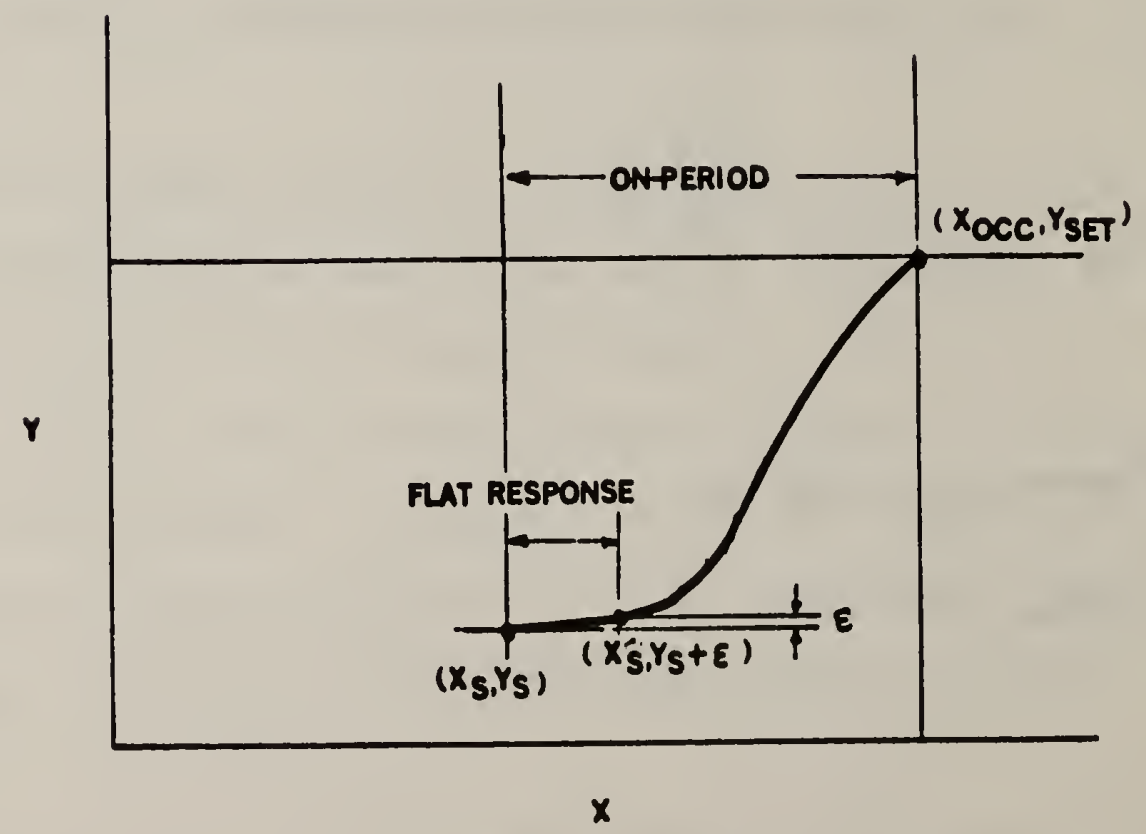

Figure A-3. The dead time during the on-period 
Consequent $1 y$, equation 5 should be used instead of equation 1 to determine the optimum start time in conjunction with equation 3 .

When the building structure has slow thermal response and the heating system has a transport delay time (dead time), the assumption made earlier about dead time is not correct. Therefore, it is necessary to take account of the duration of any "flat response" during the on-period. This "flat response" period can be defined as the time period that $\left|y-y_{S}\right|<\varepsilon$, where $y_{S}$ is the temperature at the beginning of the on-period and $\varepsilon$ is a small positive number. The dead time is then defined as the duration of the "flat response" period (see figure $\mathrm{A}-3$ ). The calculated start time must then be adjusted by the amount of dead time, $d_{O N}$. For example, if the calculated start time is $x_{S}$ under the assumptions of light structure and no dead time, the correct start time for a system with high thermal mass and a heating system with transport delay will be

$$
\mathrm{x}_{\mathrm{S}}=\mathrm{x}_{\mathrm{S}}-\mathrm{d}_{\mathrm{ON}}
$$

Since the magnitude of $\varepsilon$ strongly affects the dead time, the better the selection of $\varepsilon$, the better the estimate of the optimum start time. A value for $\varepsilon$ of $0.25^{\circ} \mathrm{C}$ was used in the computer program presented in Appendix $\mathrm{C}$. 
APPENDIX B. FLOW CHARTS OF THE COMPUTER PROGRAMS

Flow charts of the optimum start/stop control algorithm are shown in figures B-1 through B-9. The most important subroutine is the OPTSS subroutine. For detalled information, this subroutine is divided into five blocks, which are given in subsequent figures (figures B-1 through B-3). Descriptions of principal variables can be found in table 1 . 

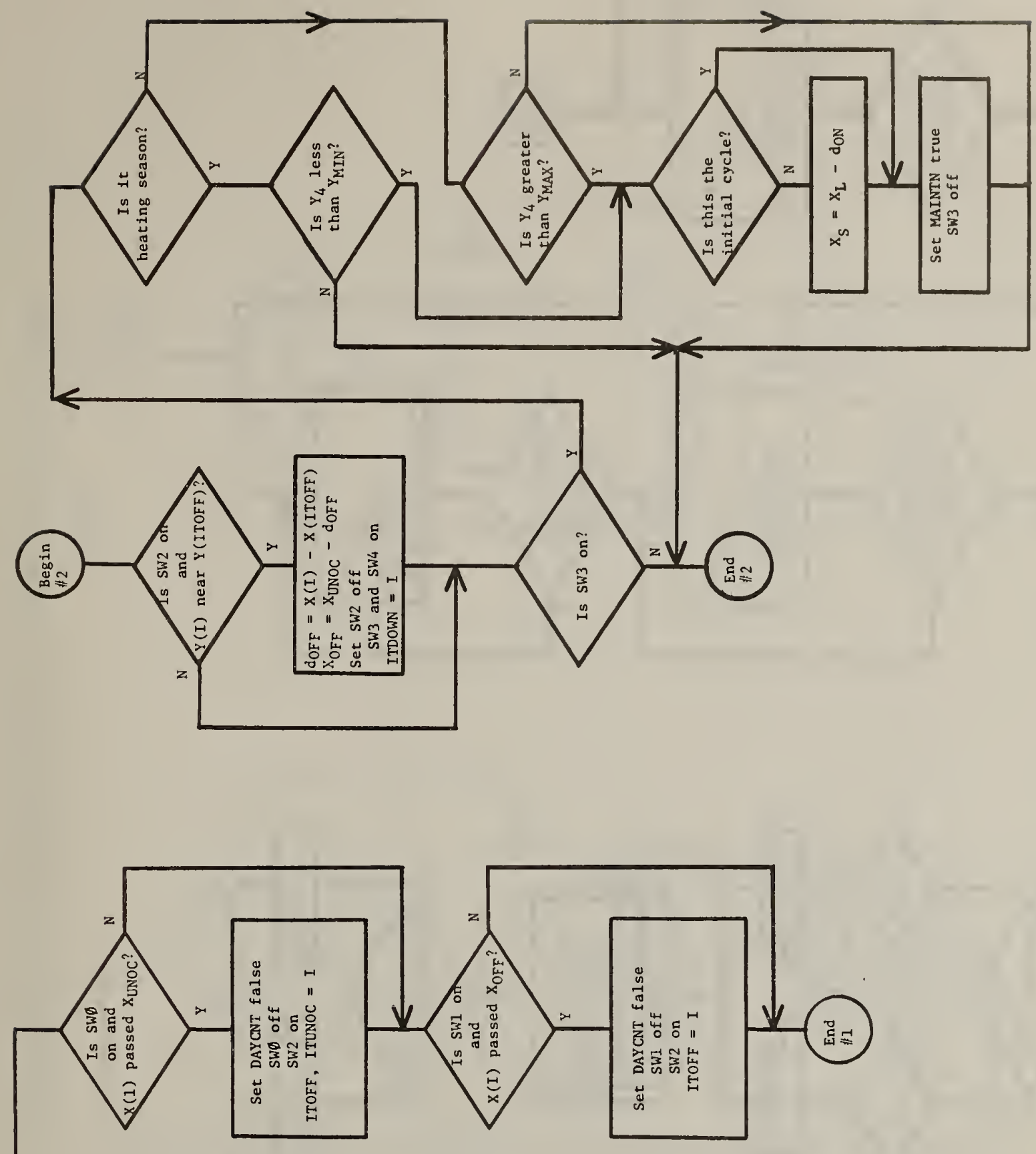

ڤ

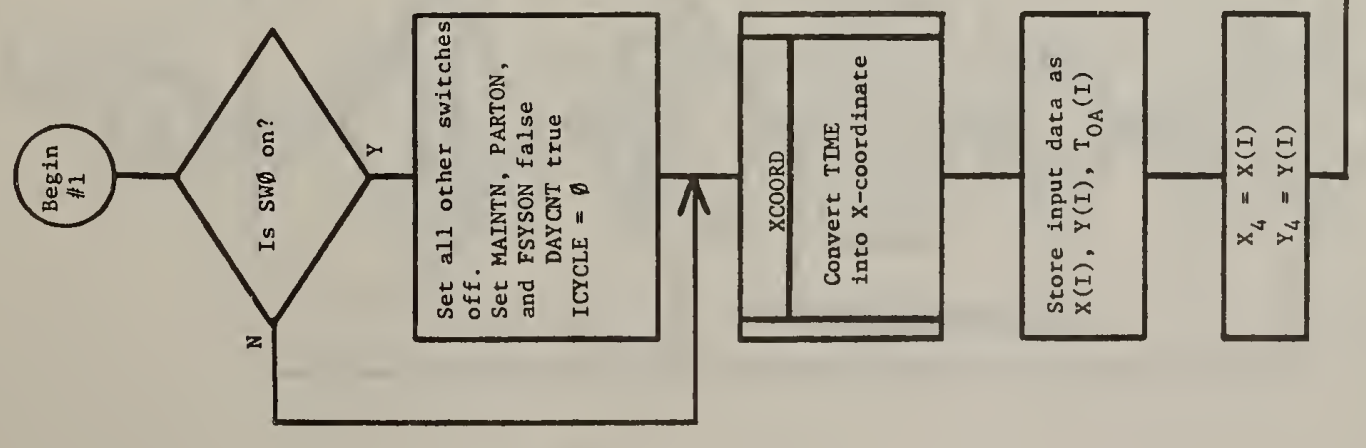



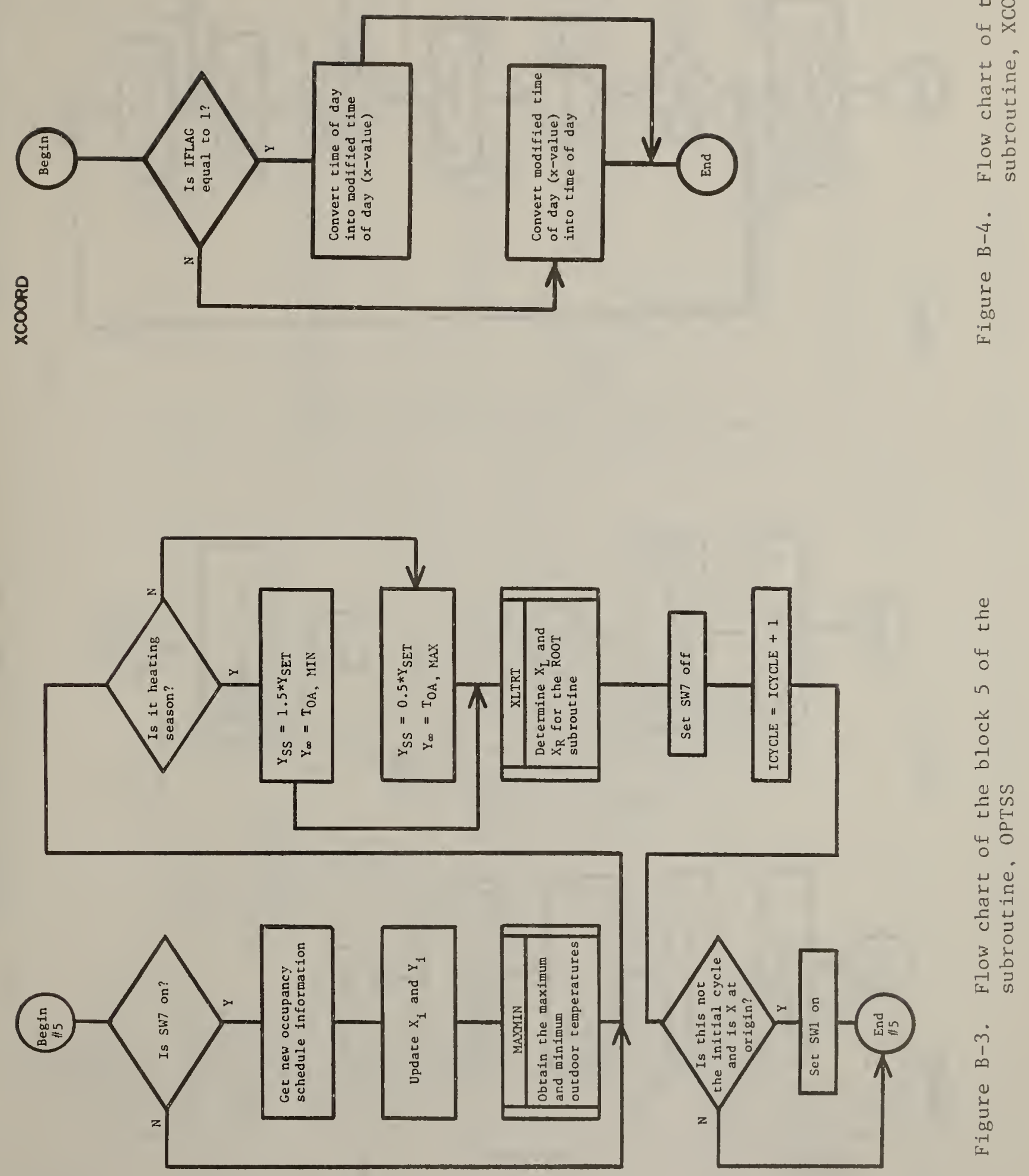

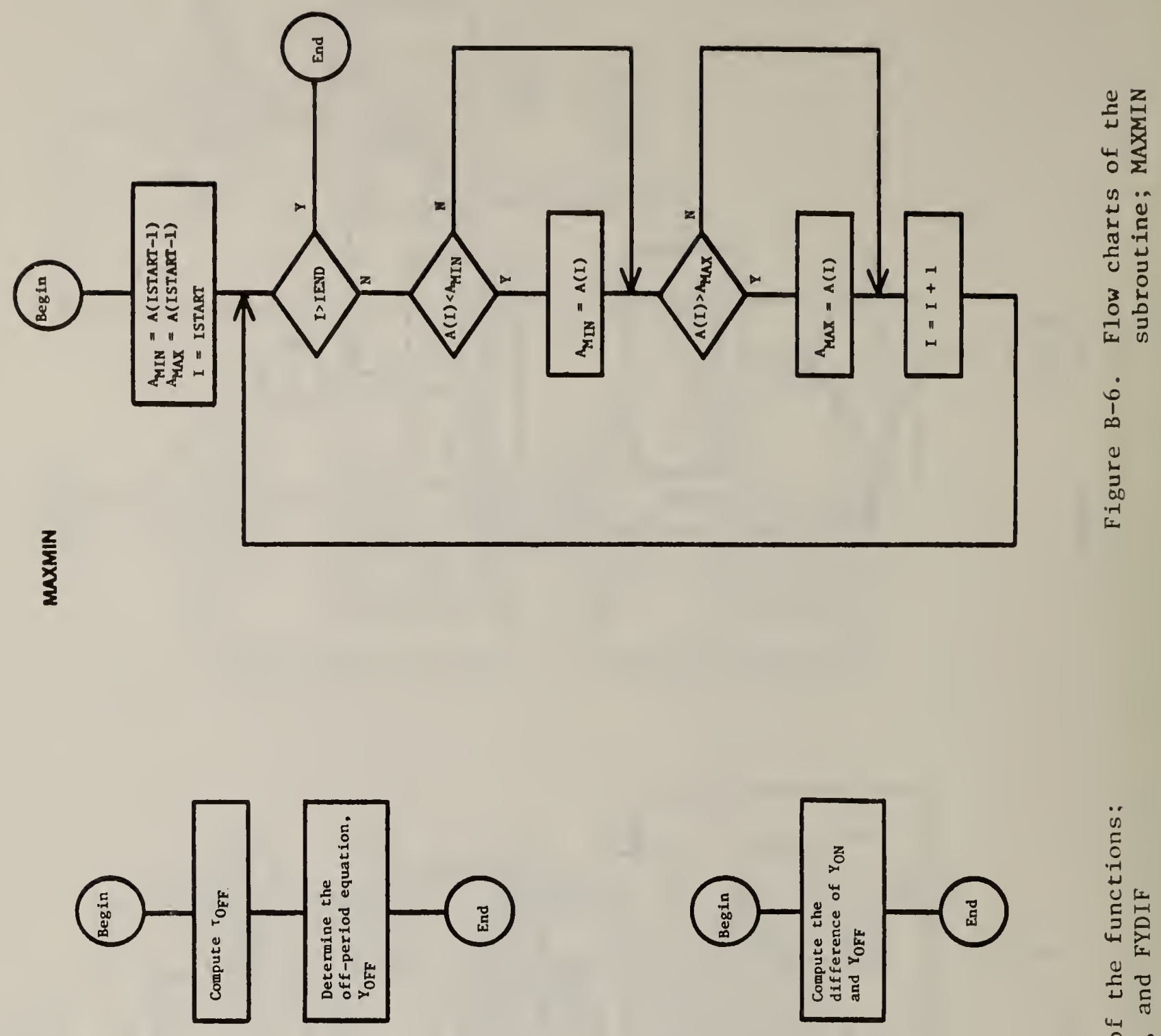

告

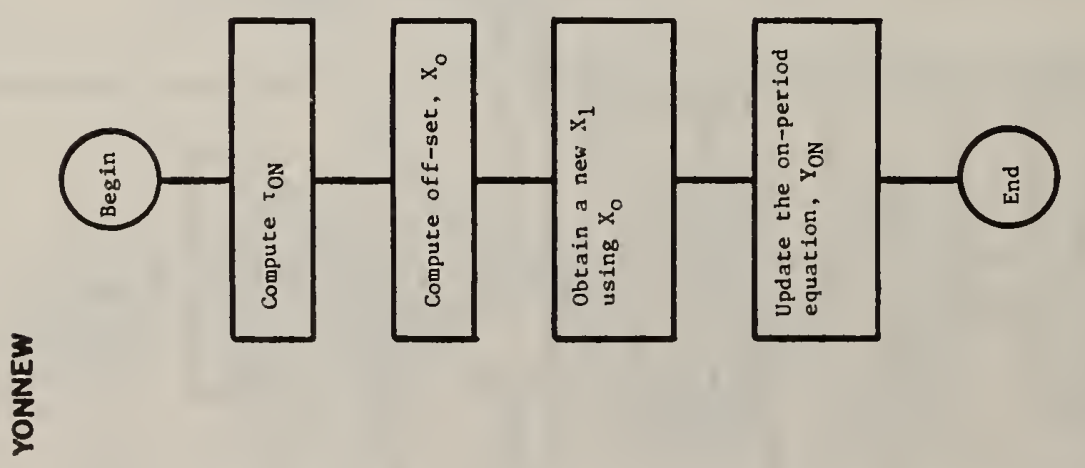

$\underset{\substack{0 \\ 0 \\ 0}}{0}$ 


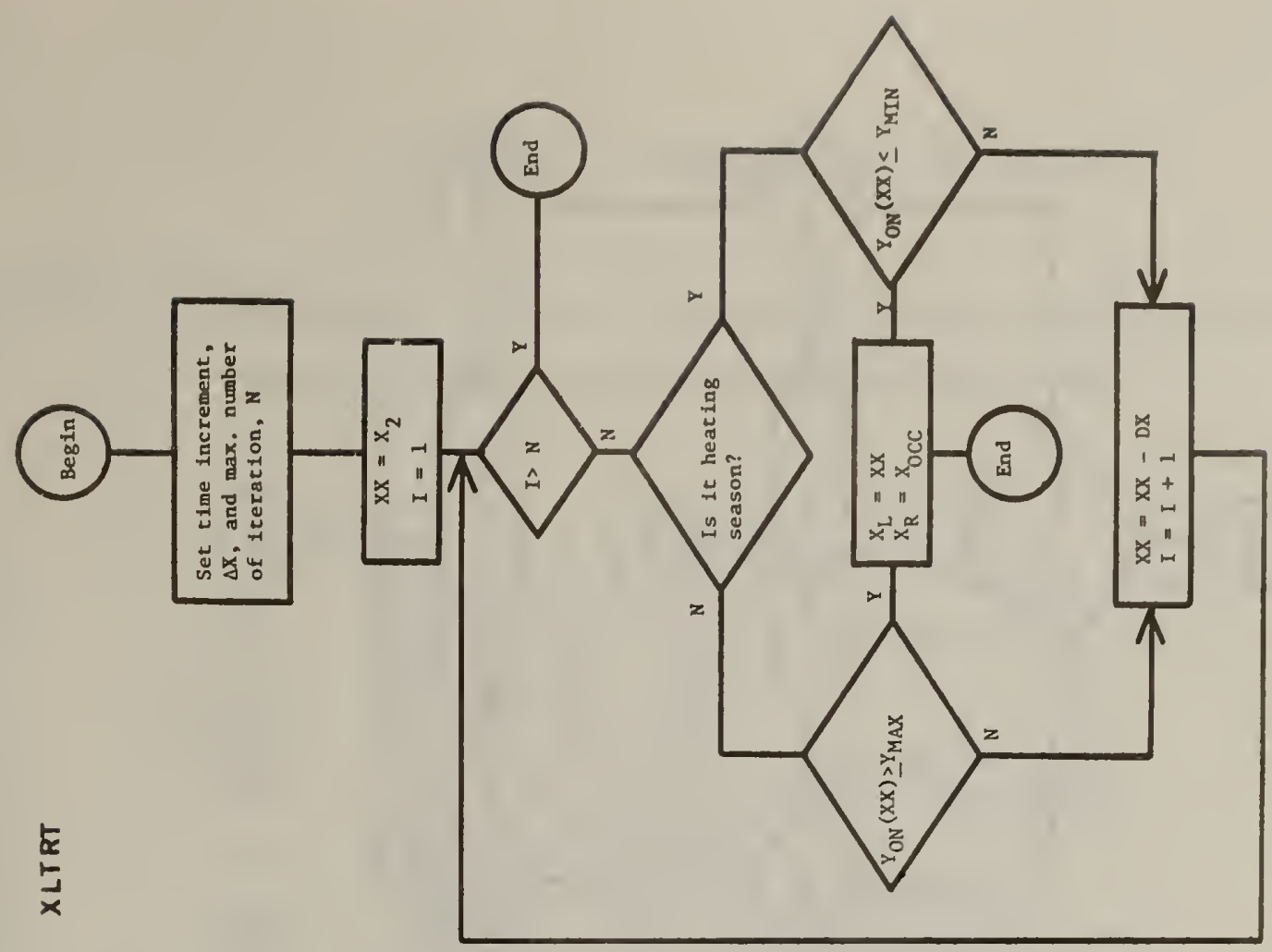



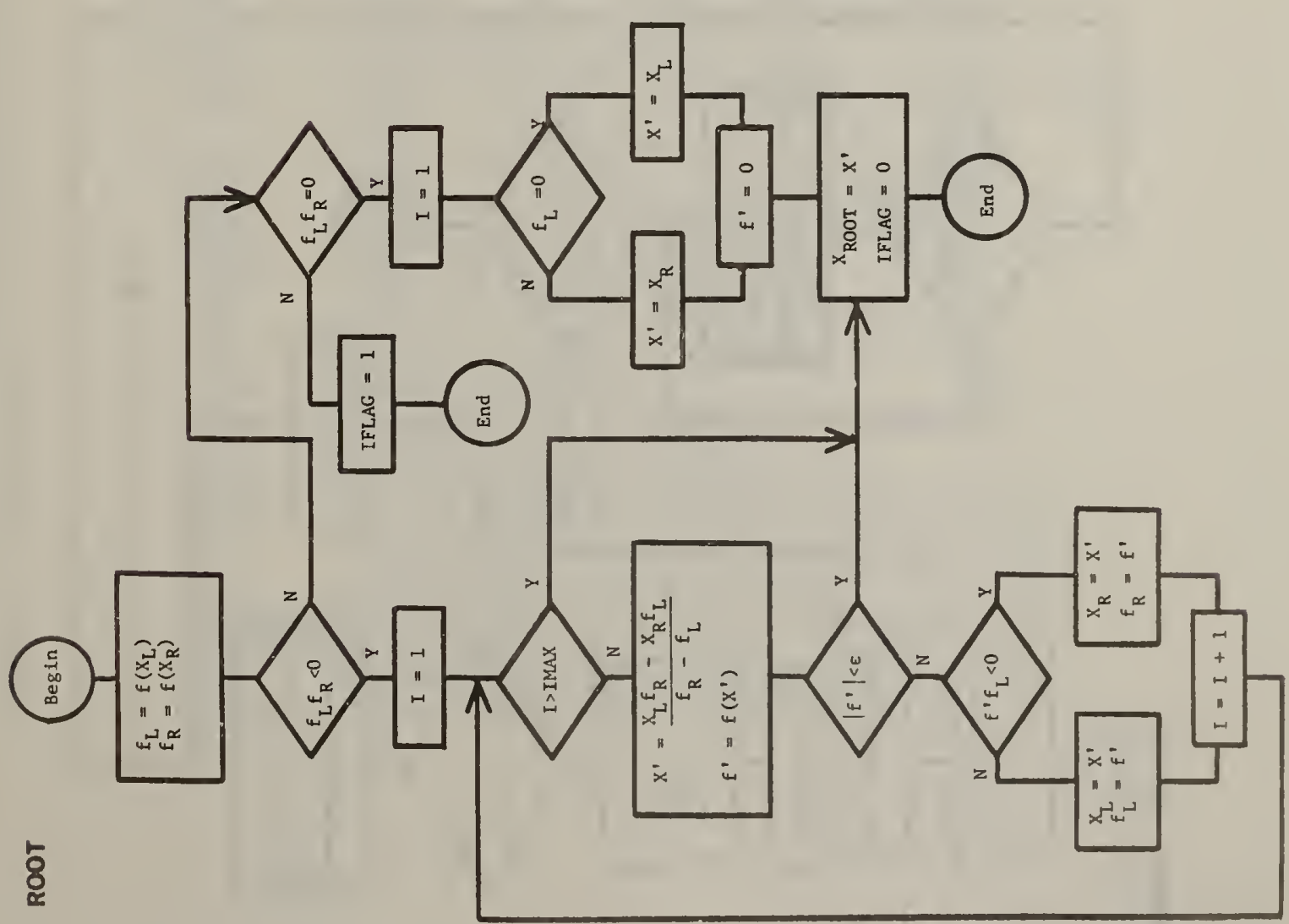



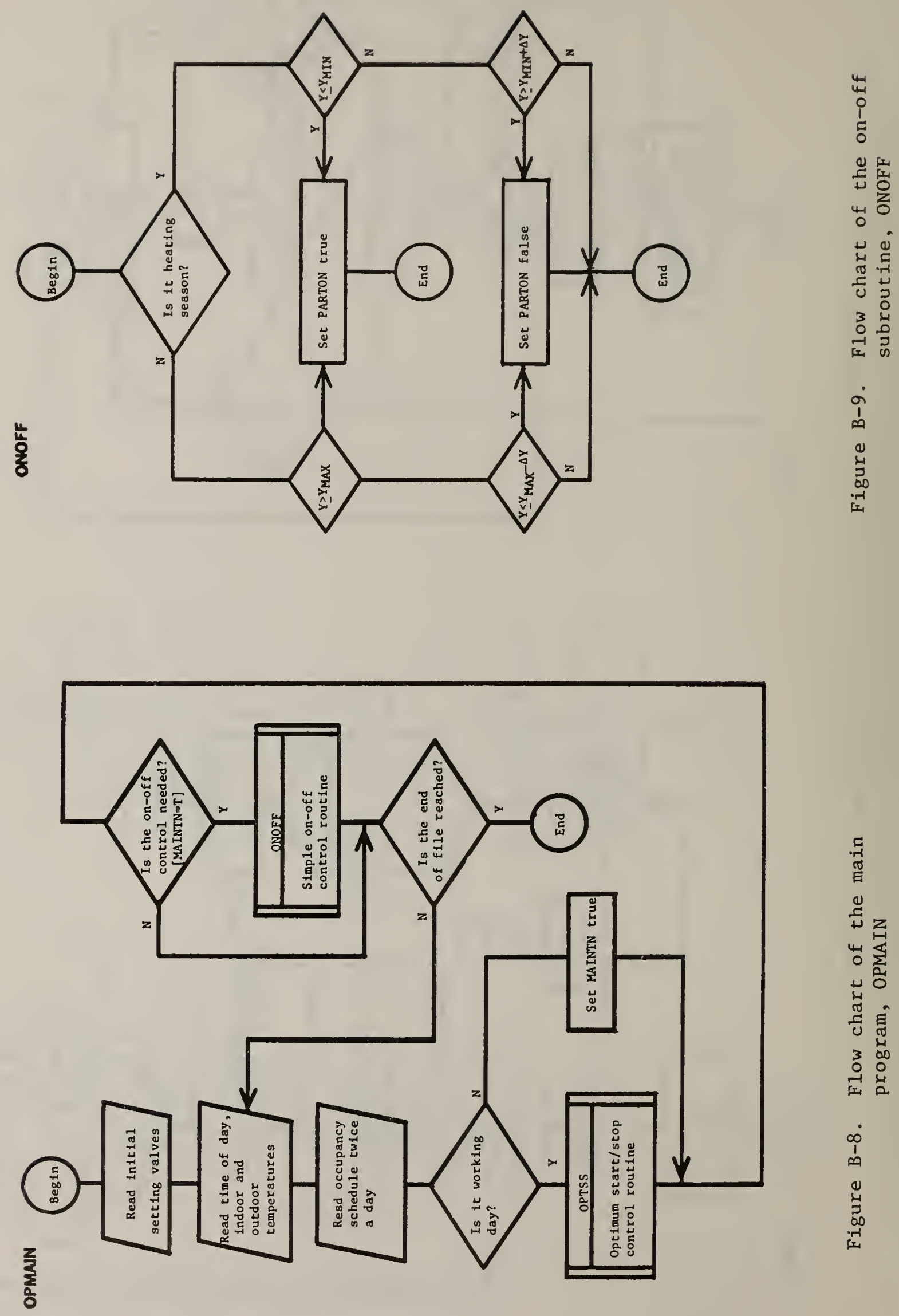

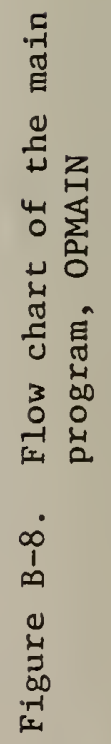




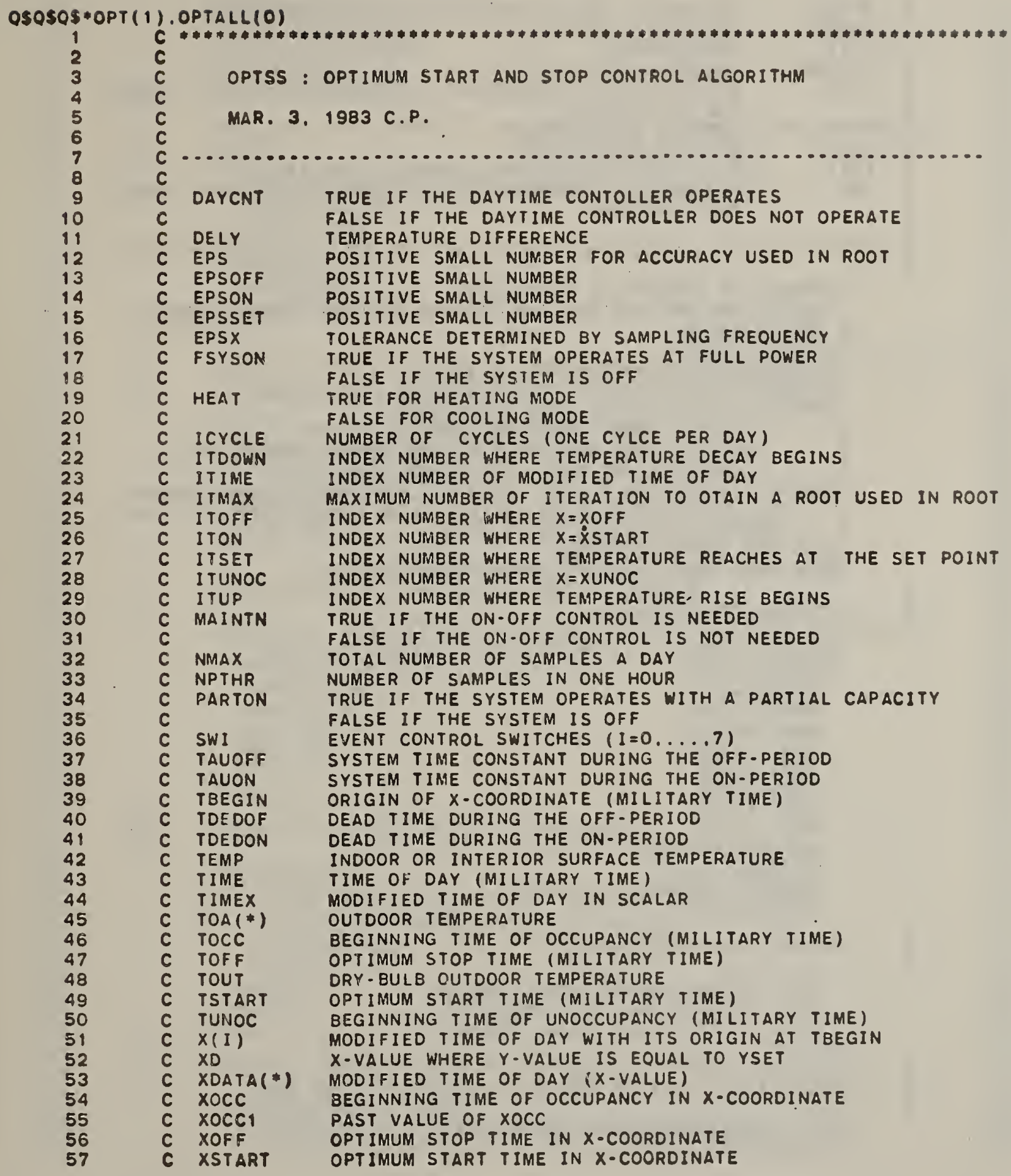




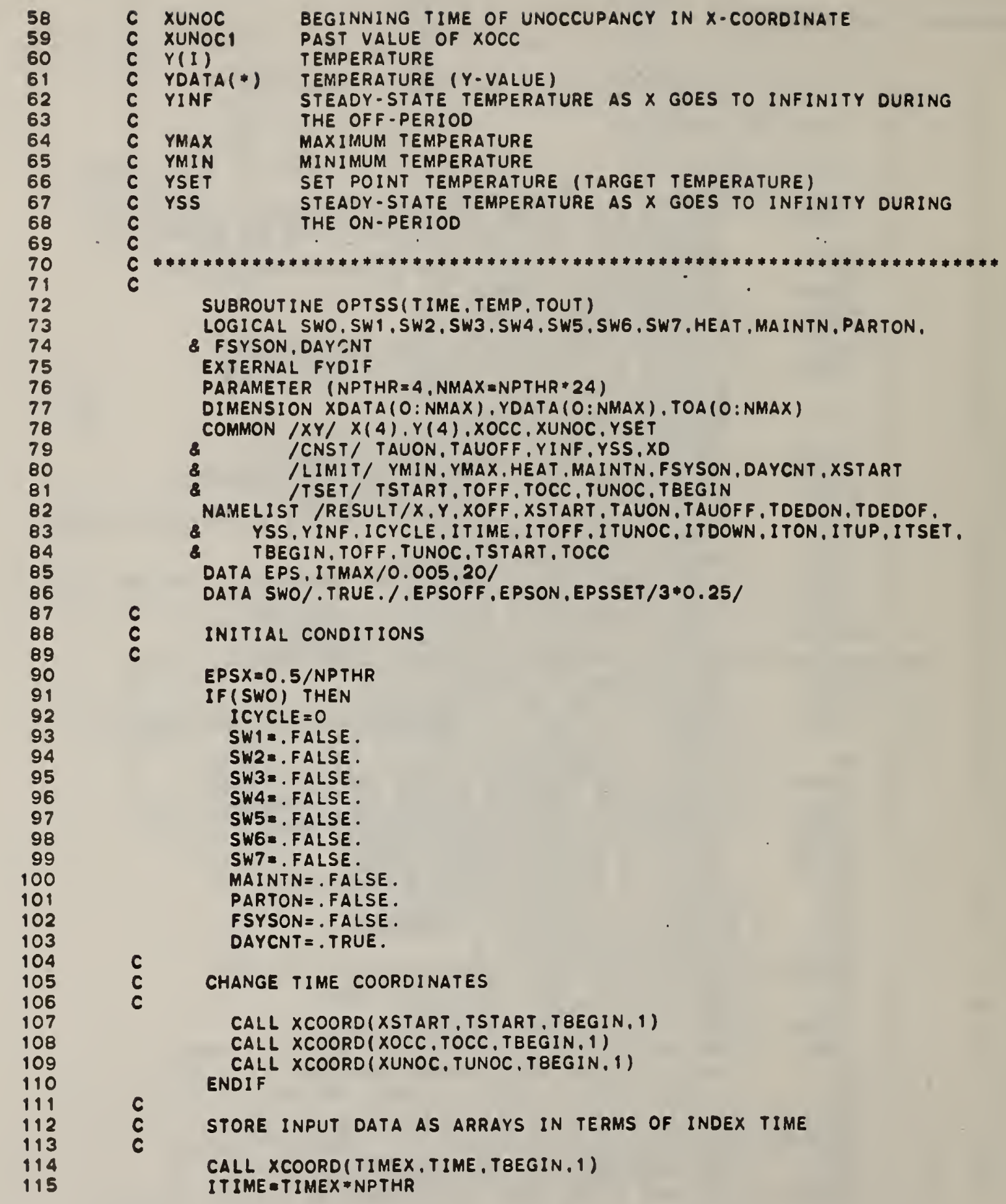




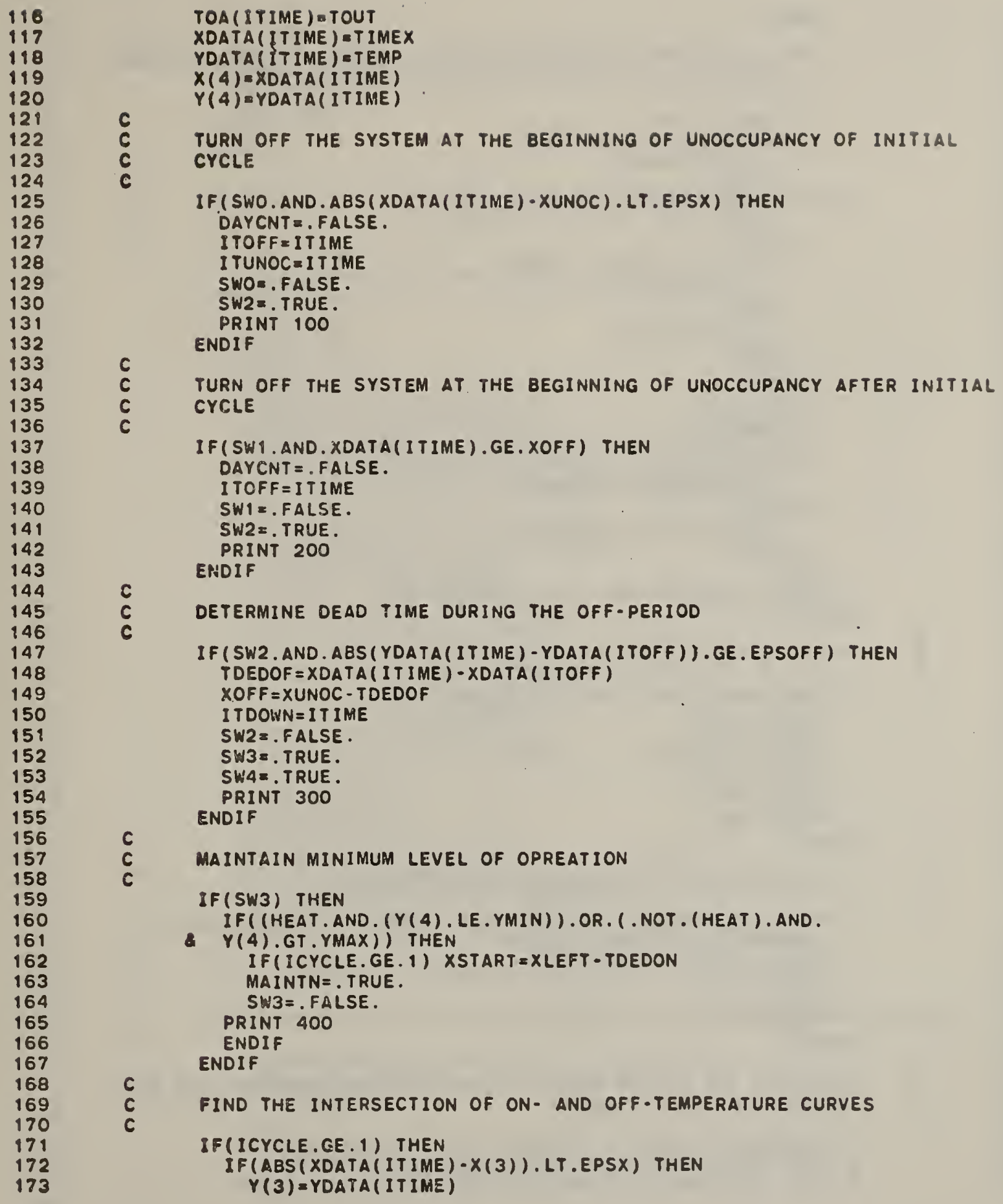

TOA (ITIME) $=$ TOUT

XDATA (ITIME) = TIMEX

YDATA ( T IME) ETEMP

$X(4)=X D A T A(I T I M E)$

$Y(4)=$ YDATA (ITIME)

$c$
$c$
$c$

TURN OFF THE SYSTEM AT THE BEGINNING OF UNOCCUPANCY OF INITIAL CYCLE

IF (SWO.AND.ABS (XDATA (ITIME) - XUNOC) - LT.EPSX) THEN DAYCNT $=$, FALSE.

ITOFF $=$ ITIME

ITUNOC I ITIME

SWOE. FALSE.

SW2 = . TRUE.

ENDIF PRINT 100

$c$
$c$
$c$

TURN OFF THE SYSTEM AT. THE BEGINNING OF UNOCCUPANCY AFTER INITIAL CYCLE

IF (SW1. AND. XDATA (ITIME), GE, XOFF) THEN DAYCNT $=$.FALSE.

ITOFF = IT IME

SWI $=$. FALSE.

SW2 $=$. TRUE.

PRINT 200$$
\text { EHDIF }
$$

C DETERMINE DEAD TIME DURING THE OFF-PERIOD

IF (SW2.AND.ABS(YDATA(ITIME)-YDATA(ITOFF)).GE.EPSOFF) THEN TDEDOF = XDATA (ITIME) - XDATA (ITOFF)

$X O F F=X U N O C-T D E D O F$

IT DOWN = IT IME

SW2 = . FALSE.

SW3 $=$. TRUE.

SW4 $=$.TRUE.

ENDIF

PRINT 300

c

MAINTAIN MINIMUM LEVEL OF OPREATION

IF (SW3) THEN

IF( (HEAT. AND. (Y (4) . LE. YMIN)) , OR . ( . NOT . (HEAT) , AND.

- Y(4).GT.YMAX)) THEN IF (ICYCLE.GE. 1) XSTART = XLEFT - TDEDON MAINTN $=$. TRUE.

$S W 3=. F A L S E$.

PRINT 400

ENDIF

ENDIF

c

FIND THE INTERSECTION OF ON- AND OFF-TEMPERATURE CURVES

IF (ICYCLE.GE. 1 ) THEN

IF (ABS (XDATA (ITIME) - X(3)) . LT.EPSX) THEN $Y(3)=$ YDATA (IT IME) 


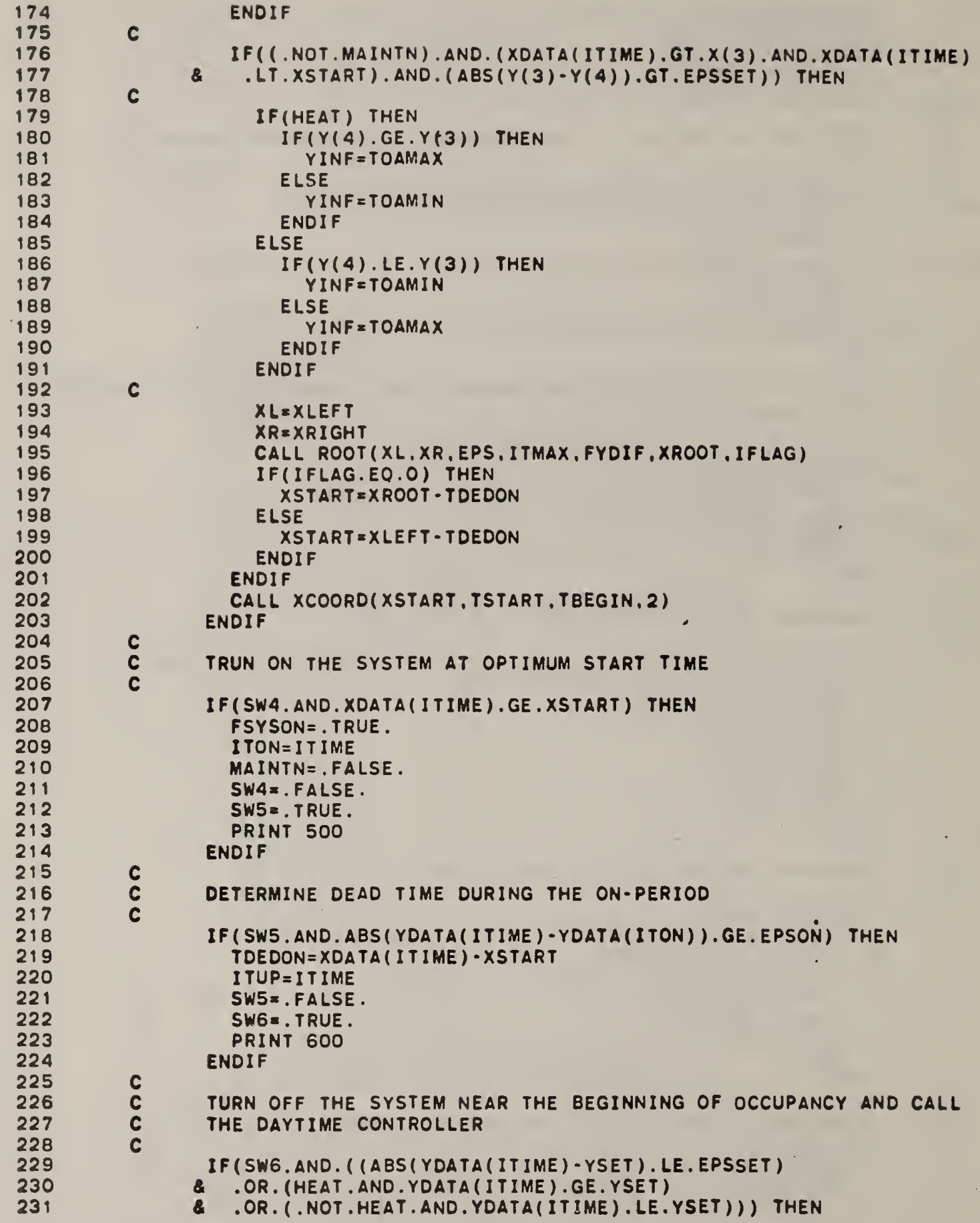




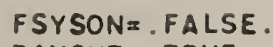

$\mathrm{C}$
$\mathrm{C}$
$\mathrm{C}$
$\mathrm{C}$

COMPUTE $X$ - AND $Y$-VALUES BASED ON PREVIOUS OBSERVATION

AND UPDATE THEM USING NEW TOCC AND TUNOC

IF(SW7) THEN

CALL XCOORD(XOFF, TOFF, TBEGIN, 2)

PRINT 900

PRINT RESULT

PRINT 900

$X O C C 1=X O C C$

XUNOC $1=$ XUNOC

IF (TUNOC.GT.TOCC) THEN

ELSE

TBEGIN $=0.5 *($ TUNOC $+24 .+$ TOCC $)$

IF (TBEGIN.GE. 24.) TBEGIN=TBEGIN-24.

\section{ENDIF}

CALL XCOORD (XOCC. TOCC.TBEGIN. 1)

CALL XCOORD (XUNOC, TUNOC, TBEGIN, 1)

$K 1=$ (ITSET - ITUP) $/ 3+I$ TUP

$K 2=(I T S E T-I T U P) * 2 / 3+I T U P$

I F (ICYCLE.EQ.O) THEN

$K 3=($ I TON - I TUNOC $) / 4+I$ TUNOC

ELSE

$K 3=($ I TON - I TDOWN $) / 4+$ I TDOWN

ENDIF

$X(1)=X D A T A(K 1)+X O C C-X O C C 1$

$X(2)=X D A T A(K 2)+X O C C \cdot X O C C 1$

$X(3)=X D A T A(K 3)+X U N O C-X U N O C 1$

$Y(1)=Y D A T A(K 1)$

$Y(2)=Y D A T A(K 2)$

$Y(3)=Y D A T A(K 3)$

XSTART $=$ XSTART + XOCC $\cdot X O C C 1$

$X O F F=X O F F+X U N O C-X U N O C 1$

CALL XCOORD(XSTART, TSTART, TBEGIN, 2)

CALL XCOORD(XOFF, TOFF, TBEGIN, 2)

C
C
C
C
C

DETERMINE MAXIMUM AND MINIMUM OUTDOOR TEMPERATURES

CALL MAXMIN(TOA, TOAMIN, TOAMAX, NMAX)

COMPUTE CONSTANTS FOR ON-AND OFF-PERIOD TEMPERATURE EQUATIONS

IF (HEAT) THEN

YSS $=1.5 *$ YSET

$Y I N F=$ TOAMIN

ELSE

YSS $=0.5 *$ YSET

$Y I N F=$ TOAMAX

ENDIF

c 


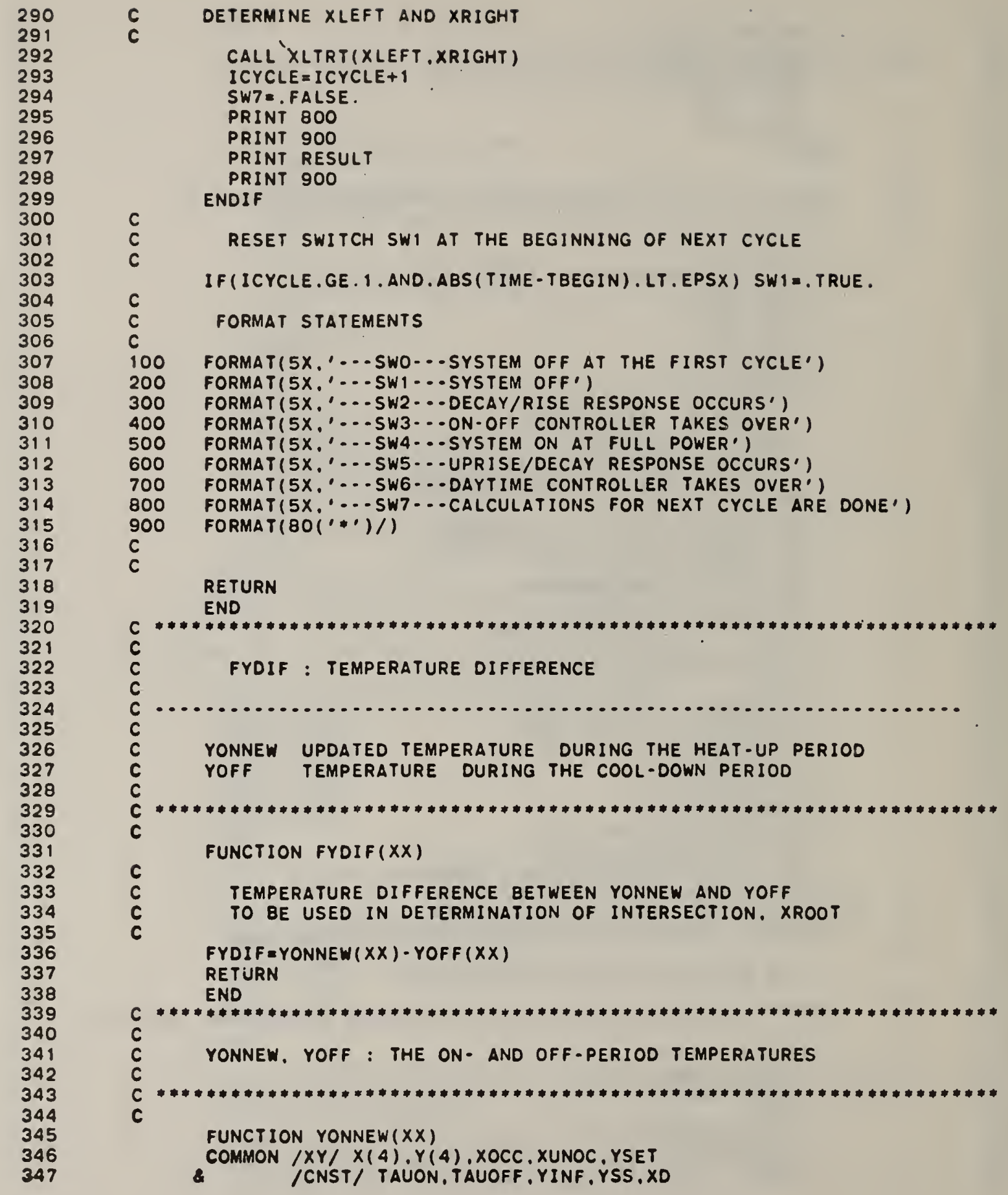




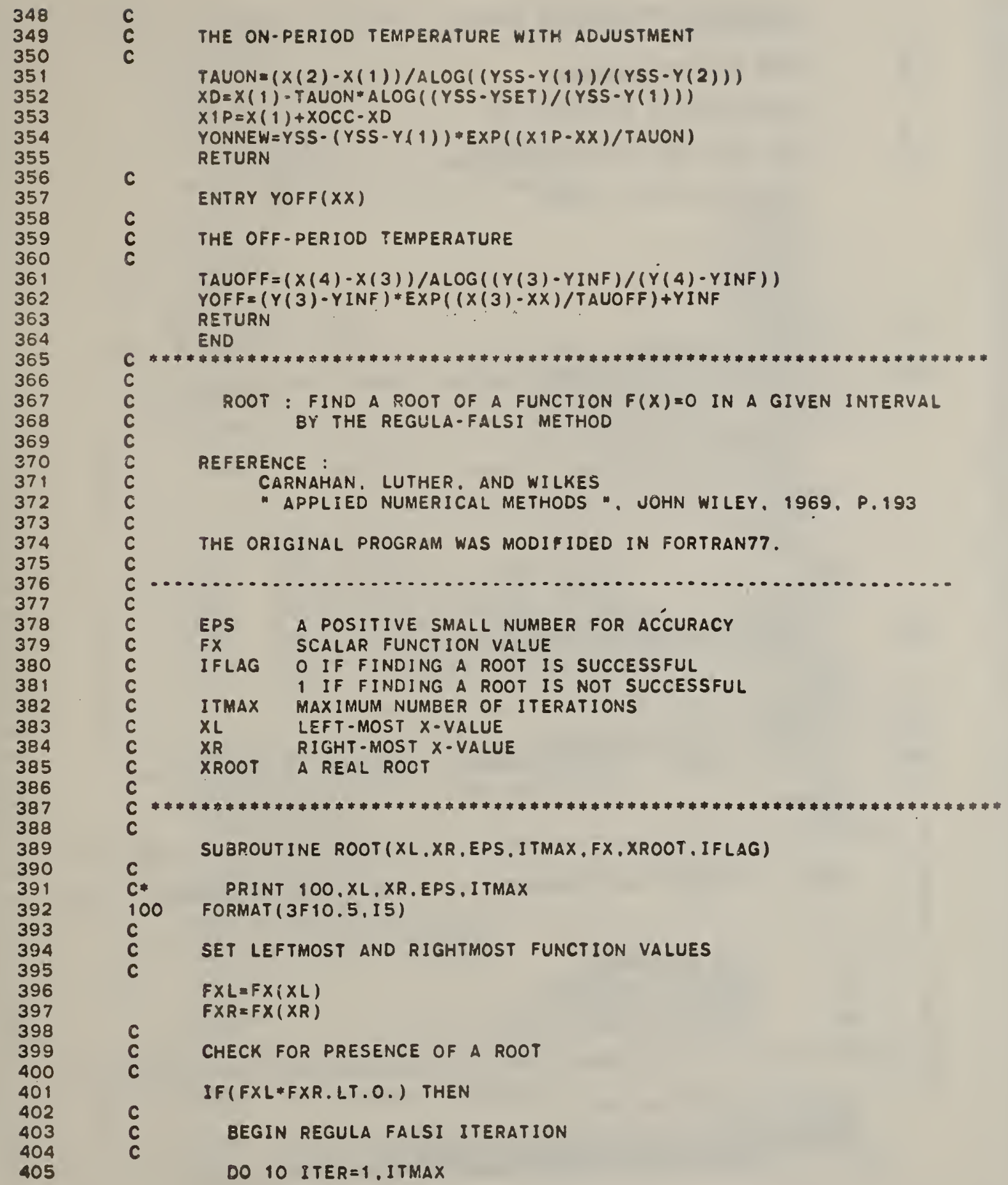




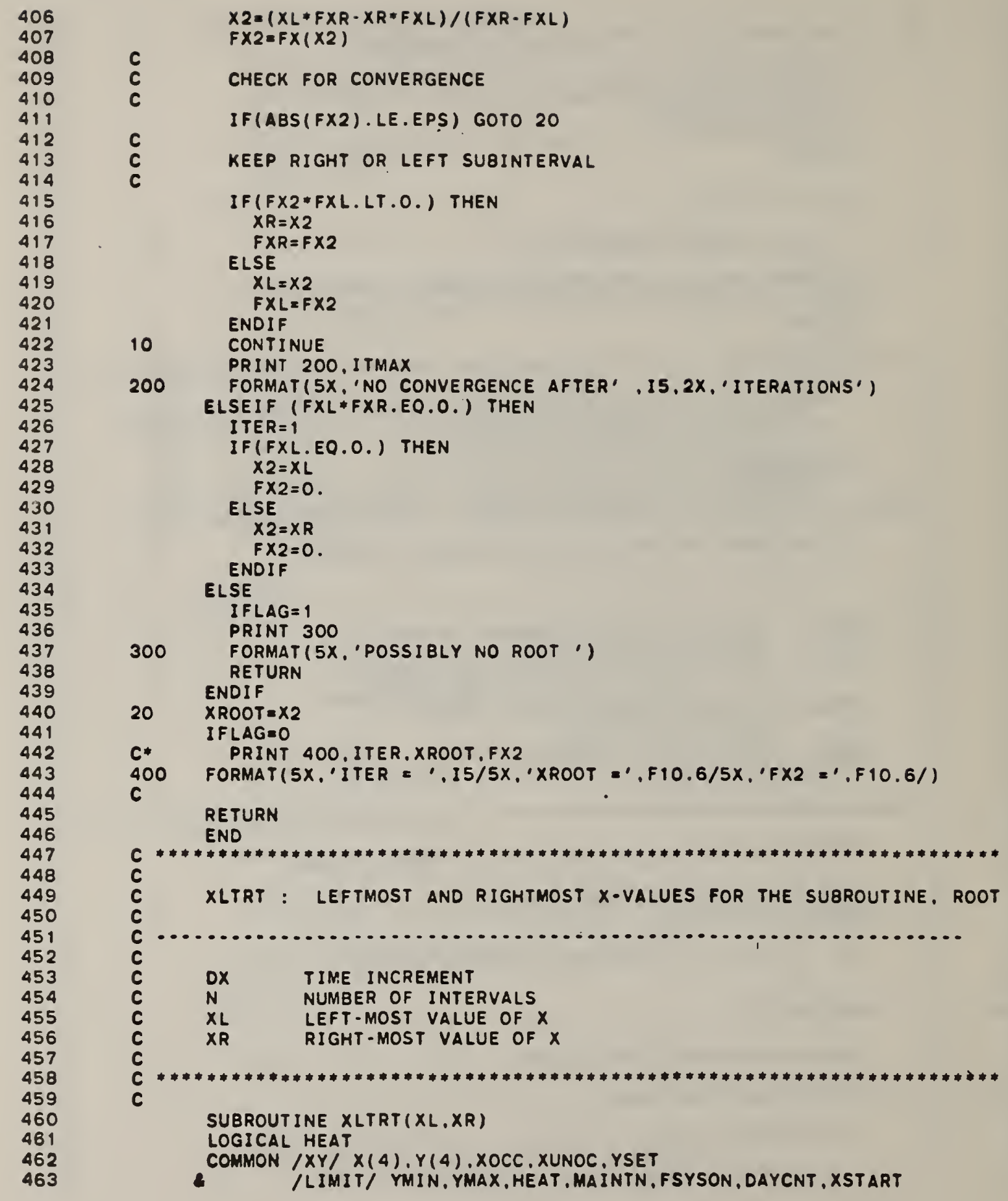




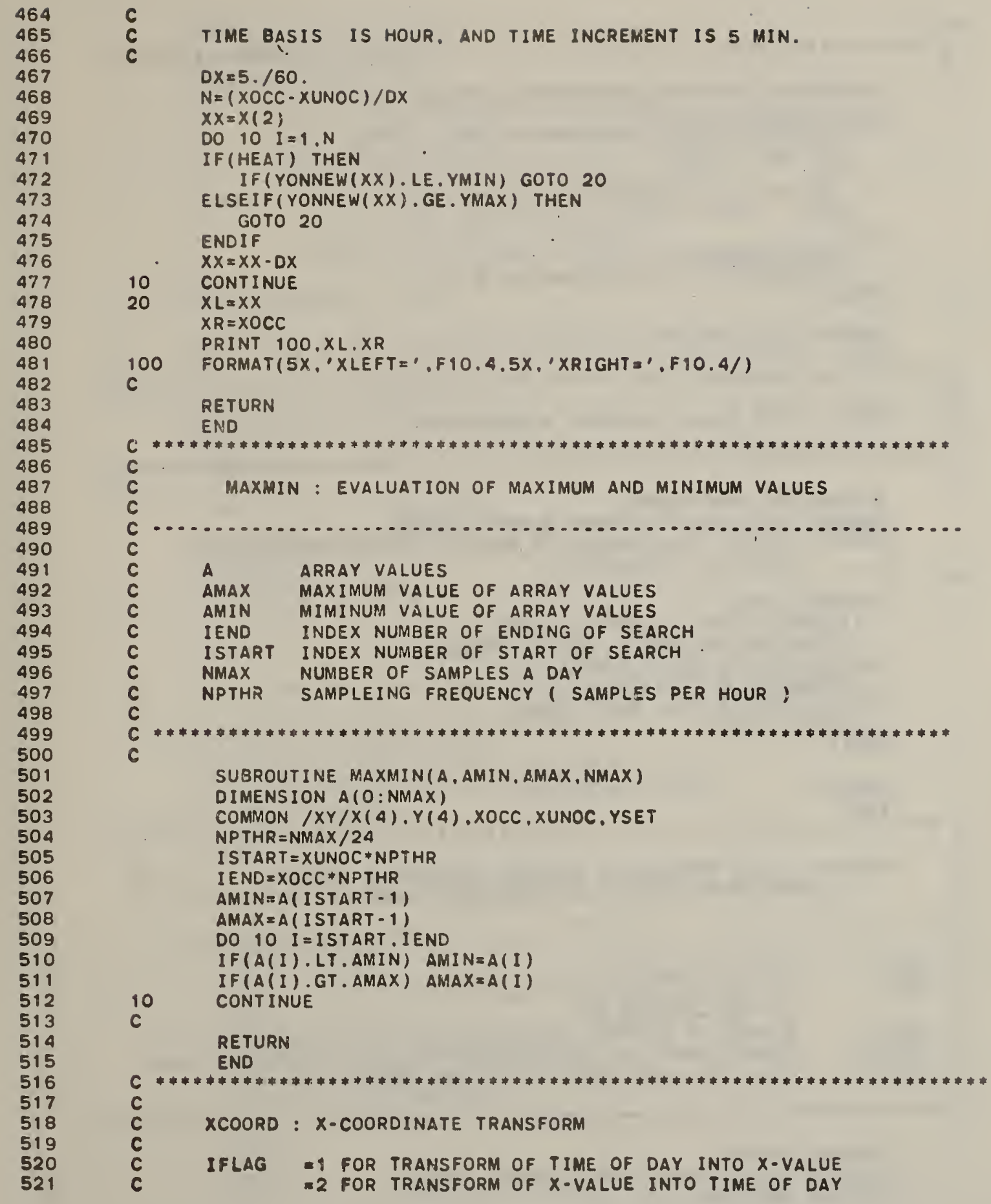




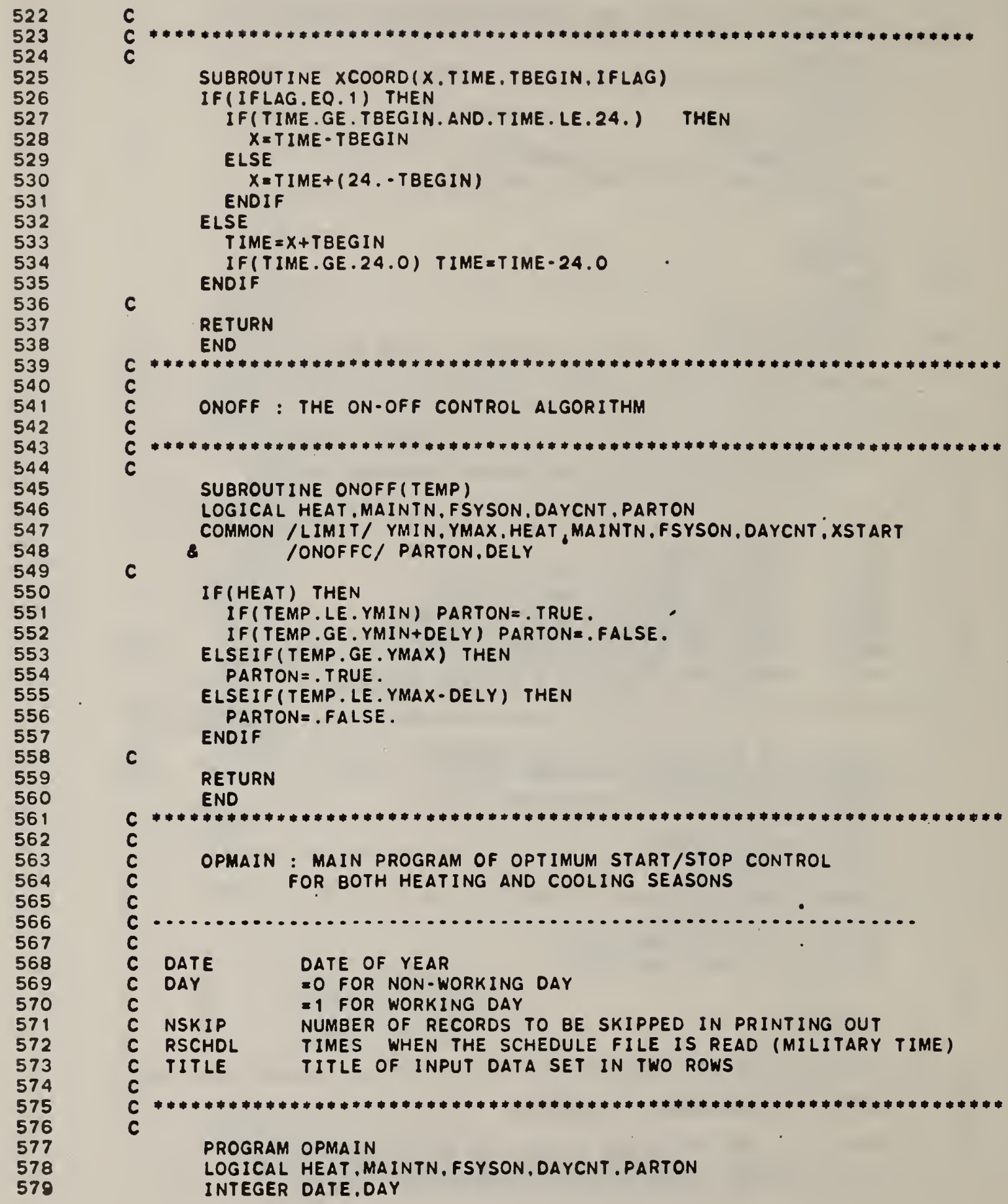
c 


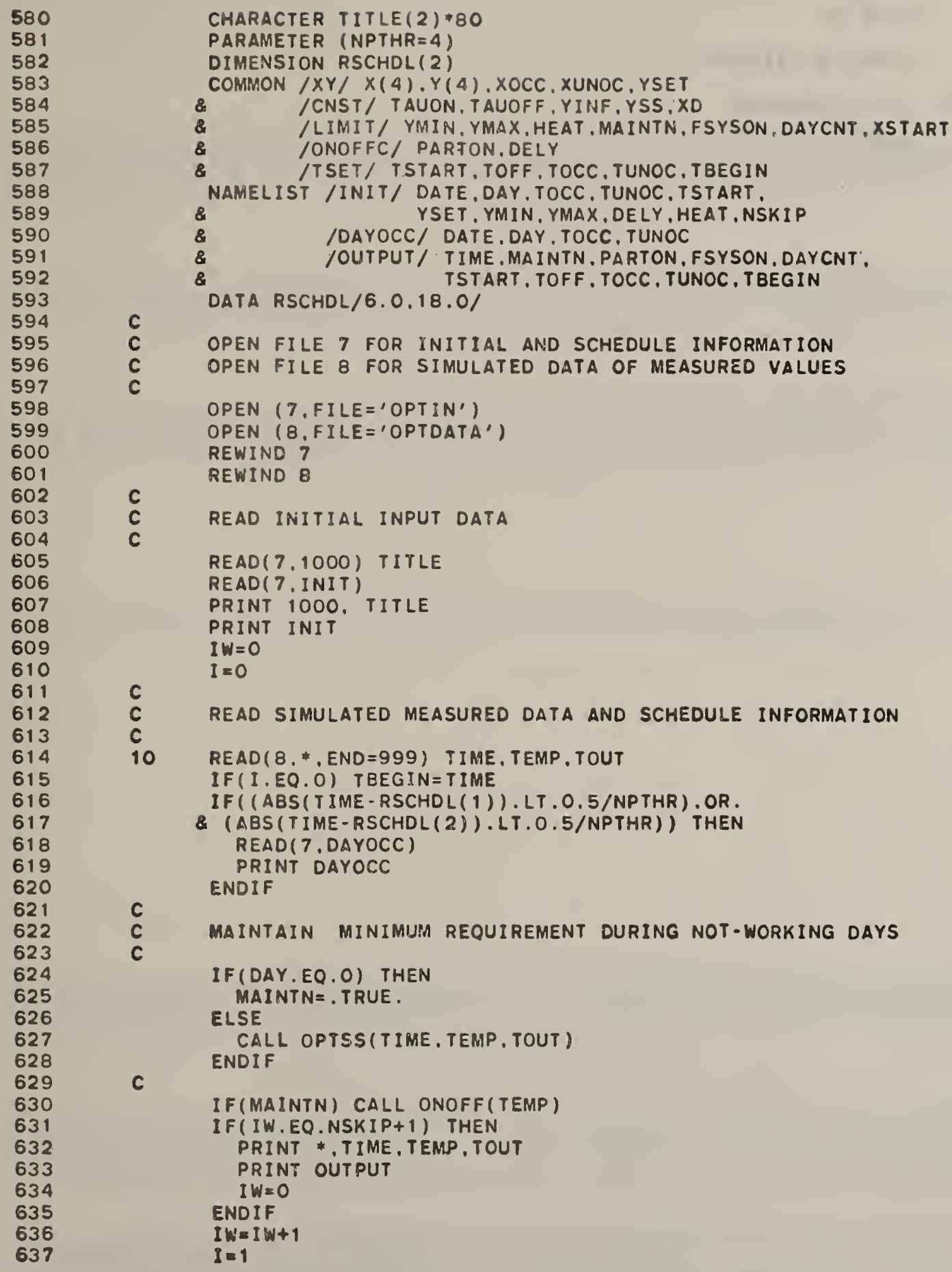




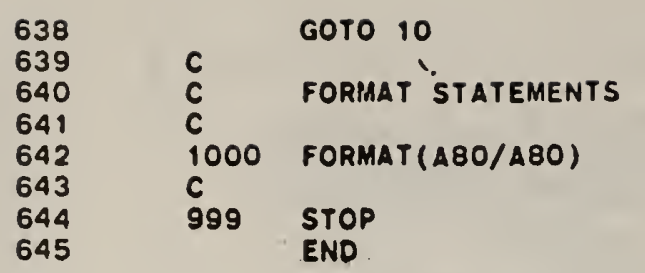


APPENDIX D. SAMPLE INPUT AND OUTPUT OF THE PROGRAM

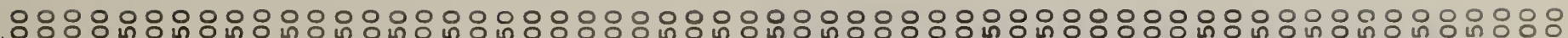

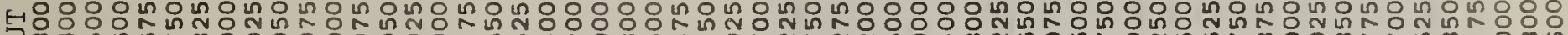

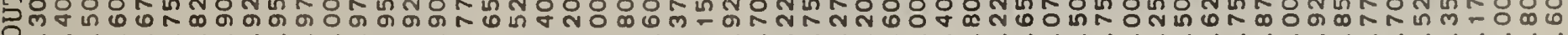

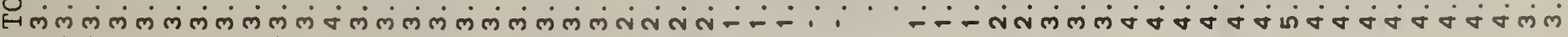

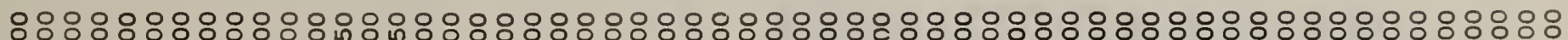

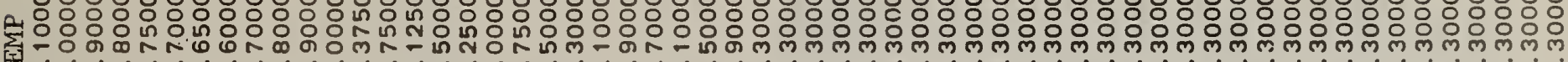

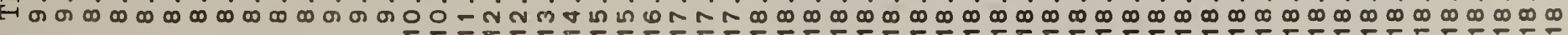

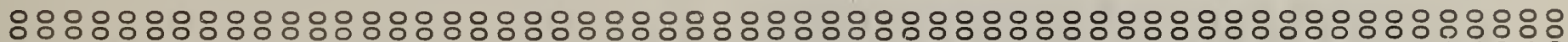

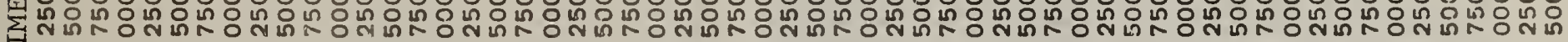

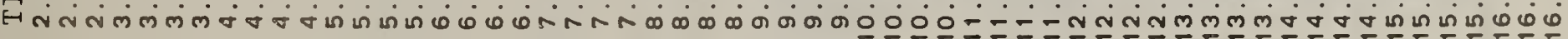

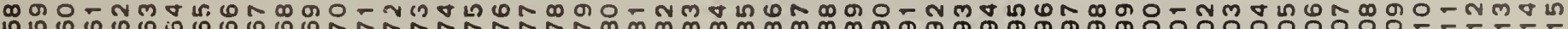
แ

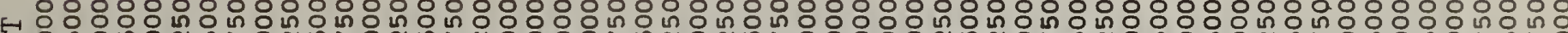

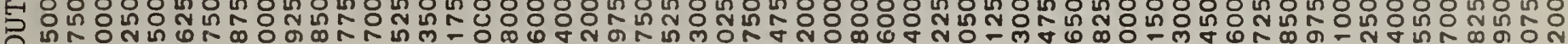

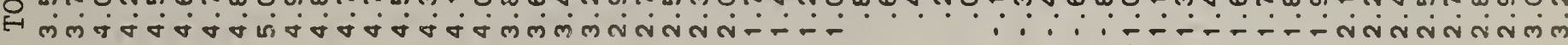

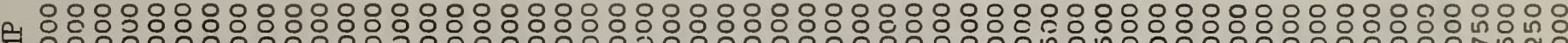

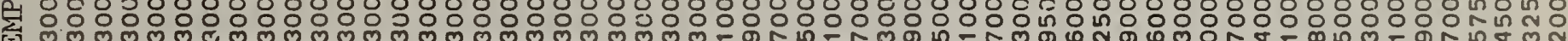

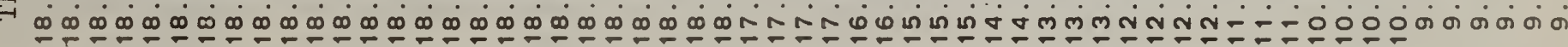

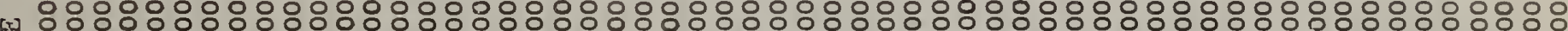
س

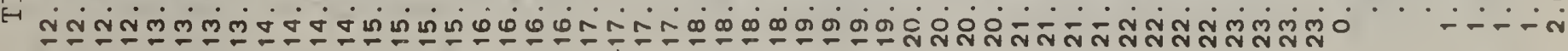




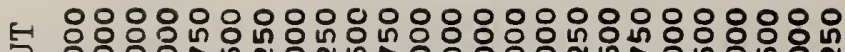

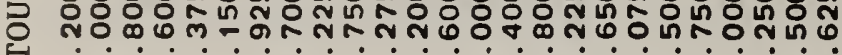

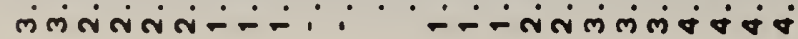
.

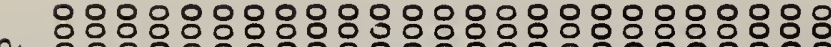

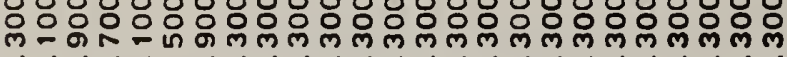
Un

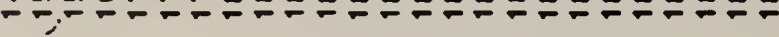

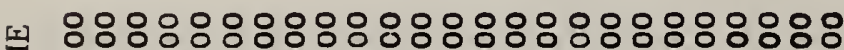
ผูก ํำ

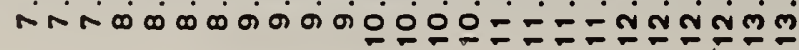

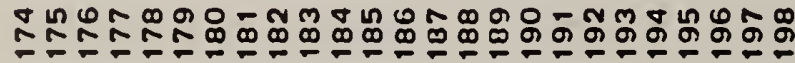

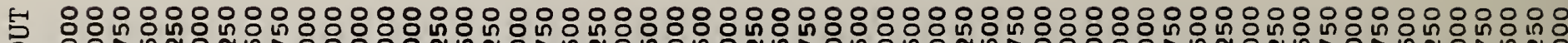

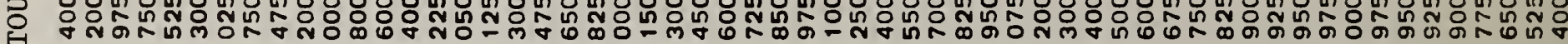

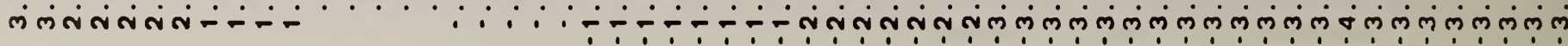

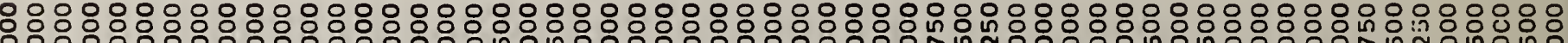

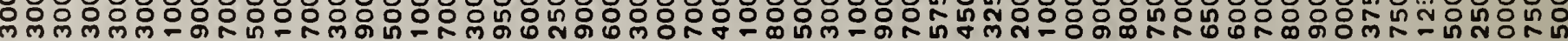

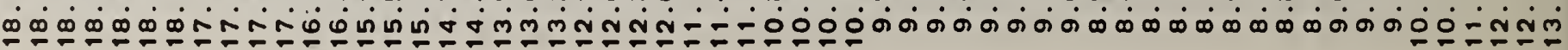

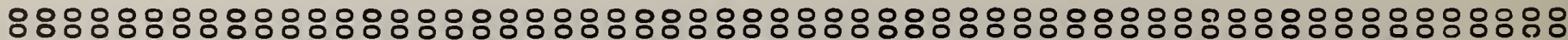

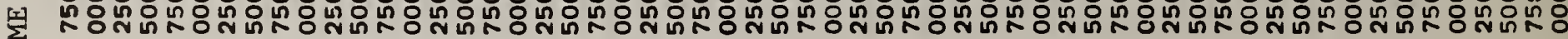

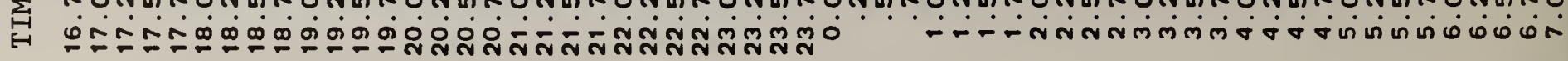

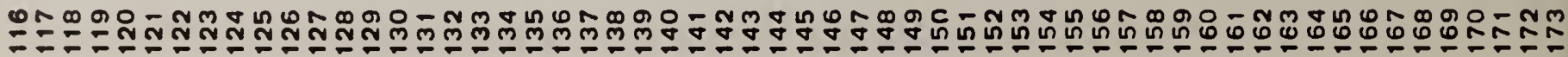




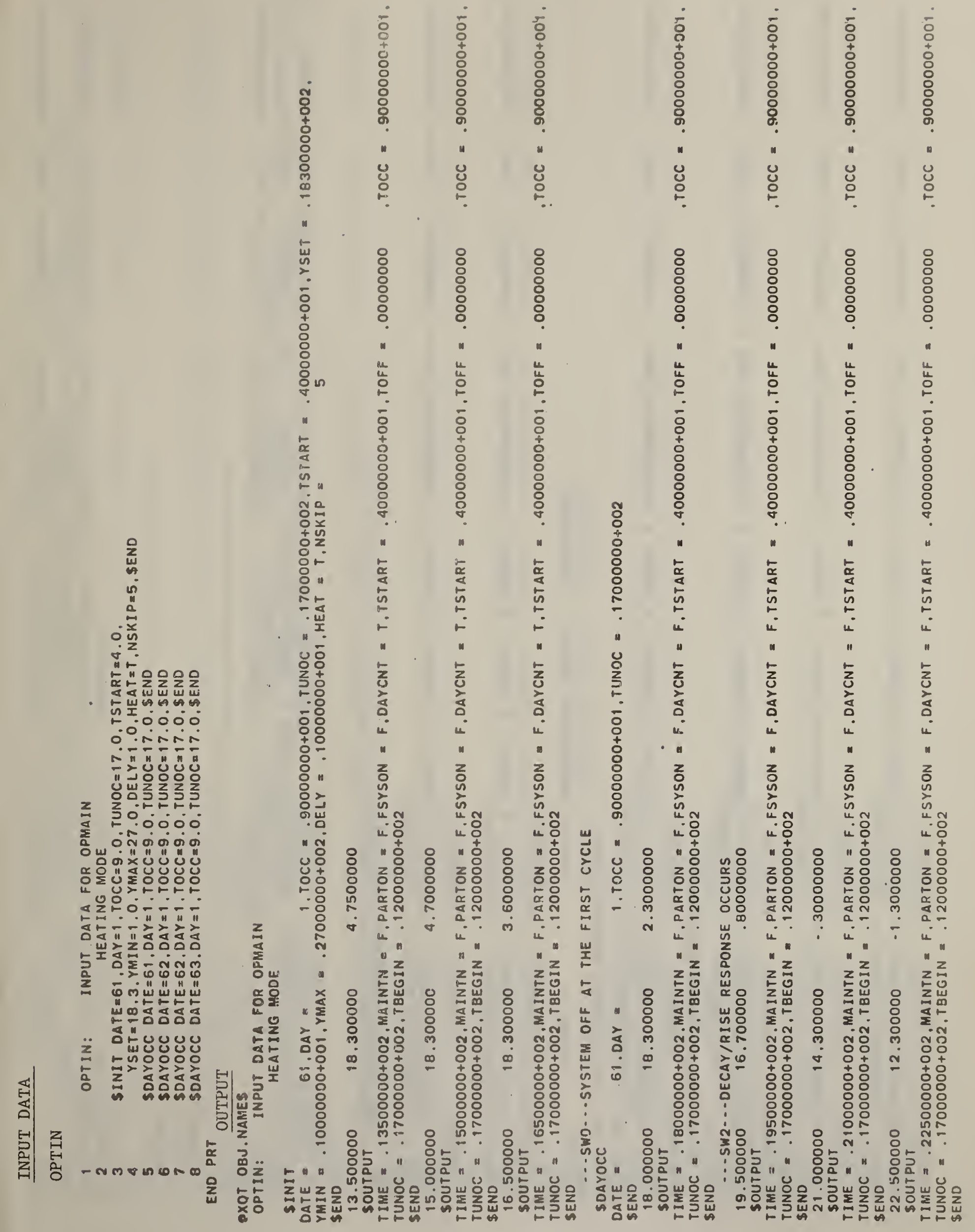



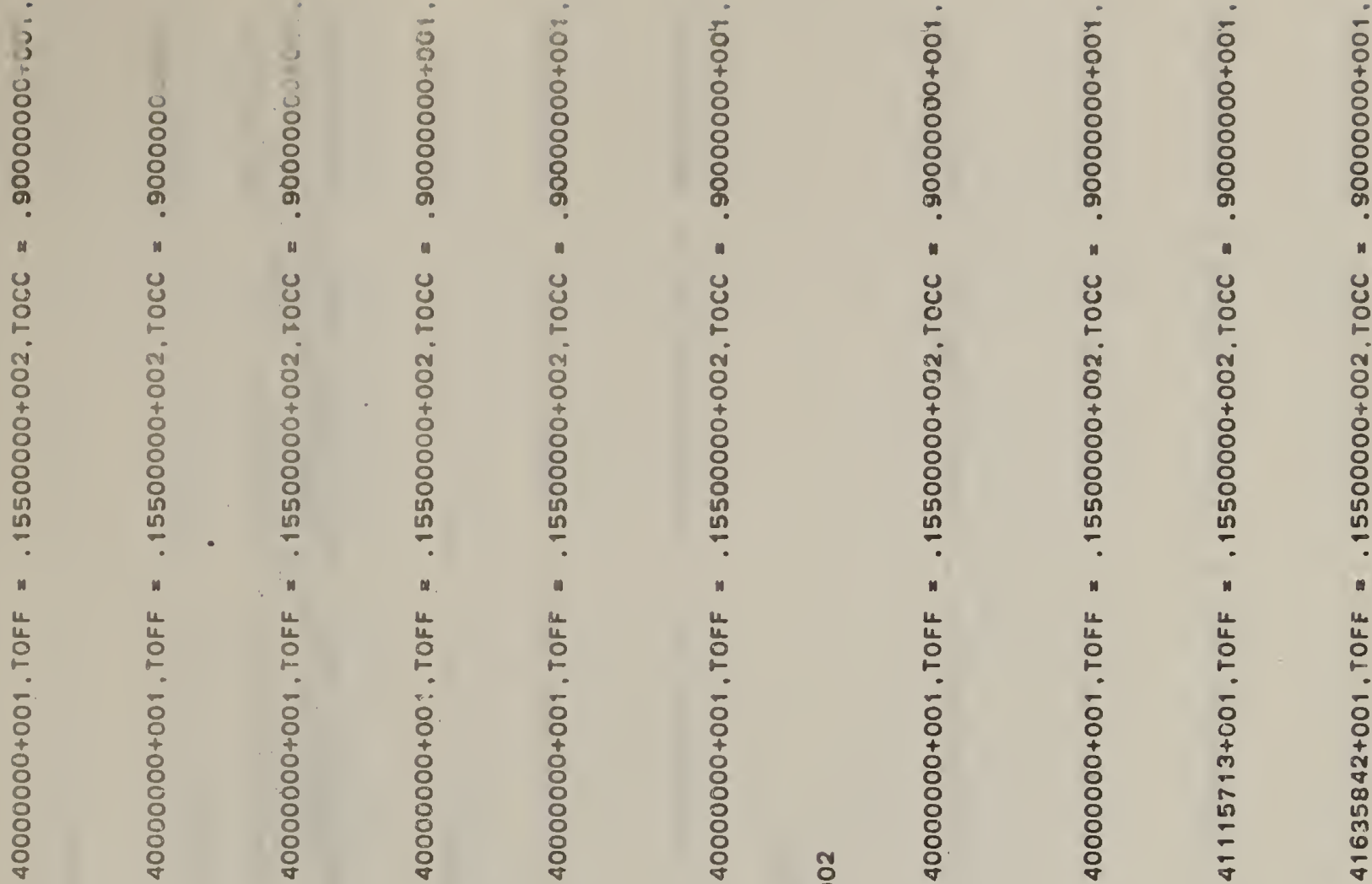

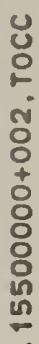

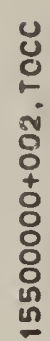

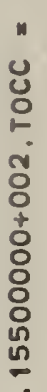

ㄴ.

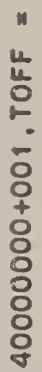
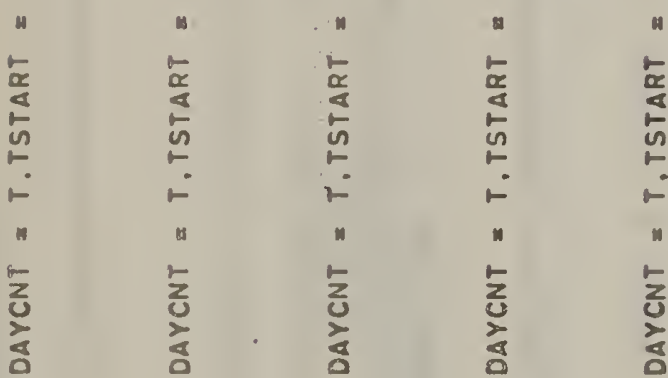

$\stackrel{5}{a}$<smiles>[B]BOBO[B]</smiles>

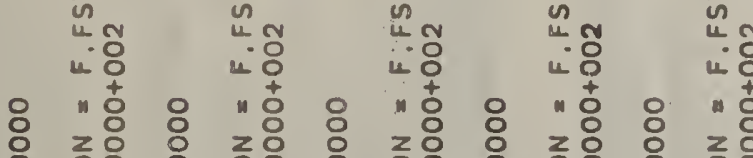

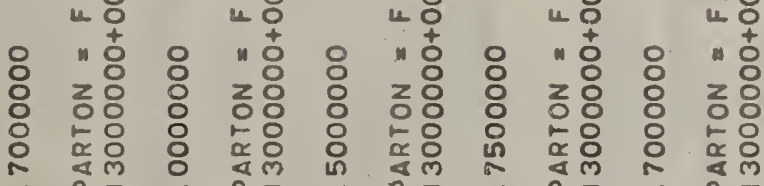

- u-

- \& $a ?$

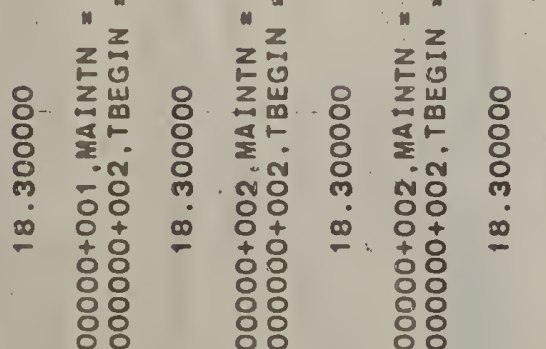

*

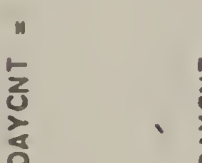

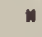

는

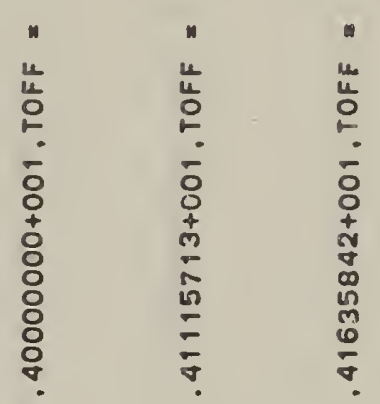

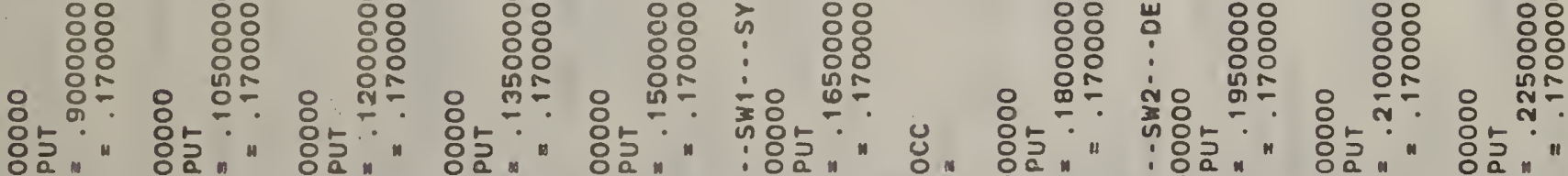

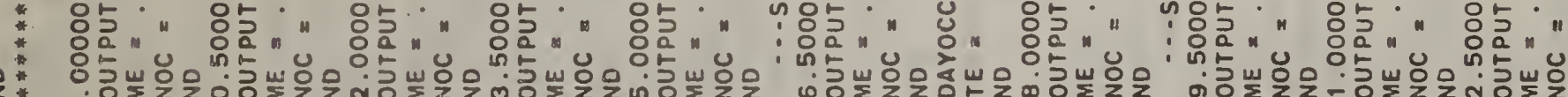

羔 


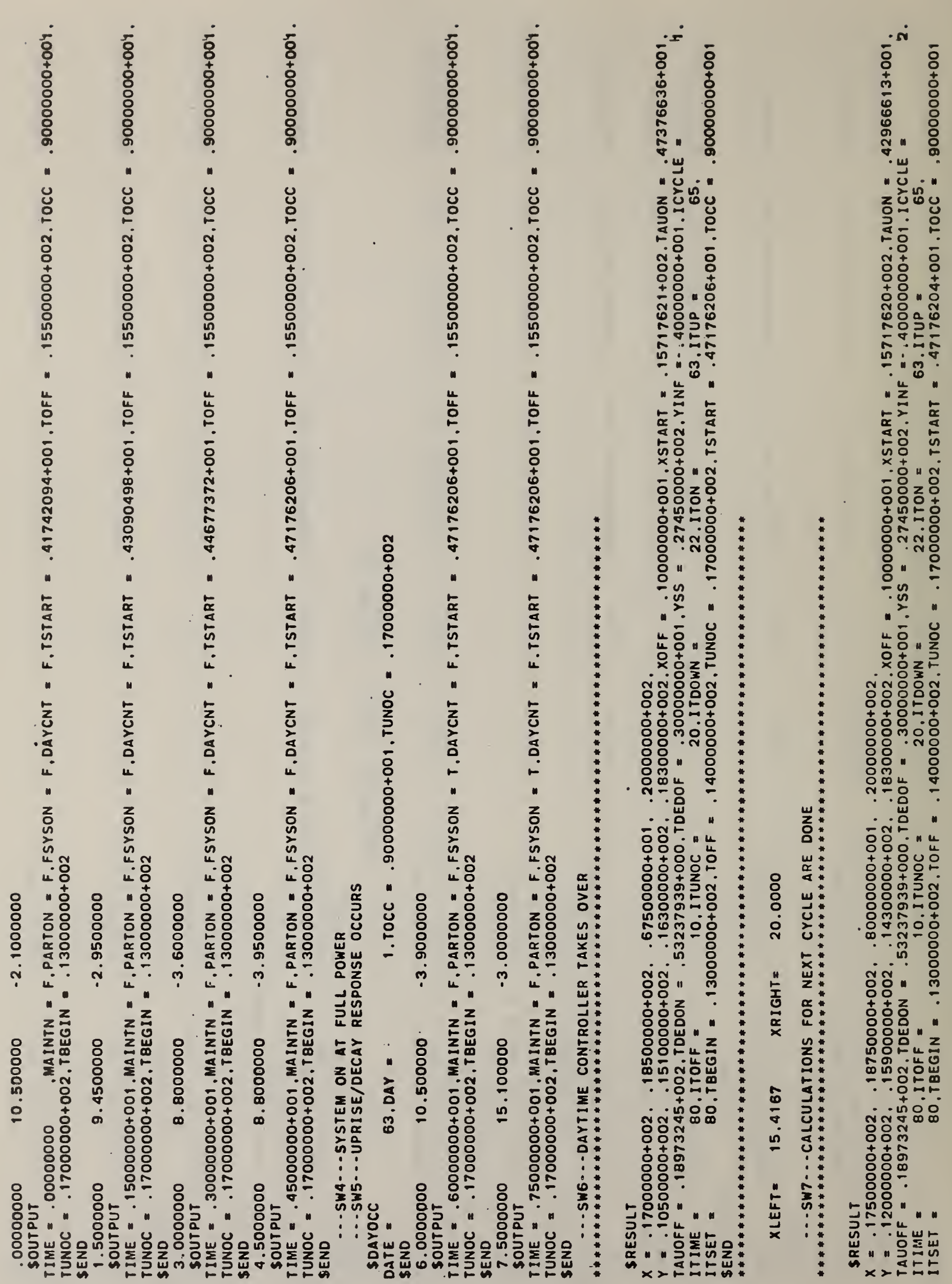




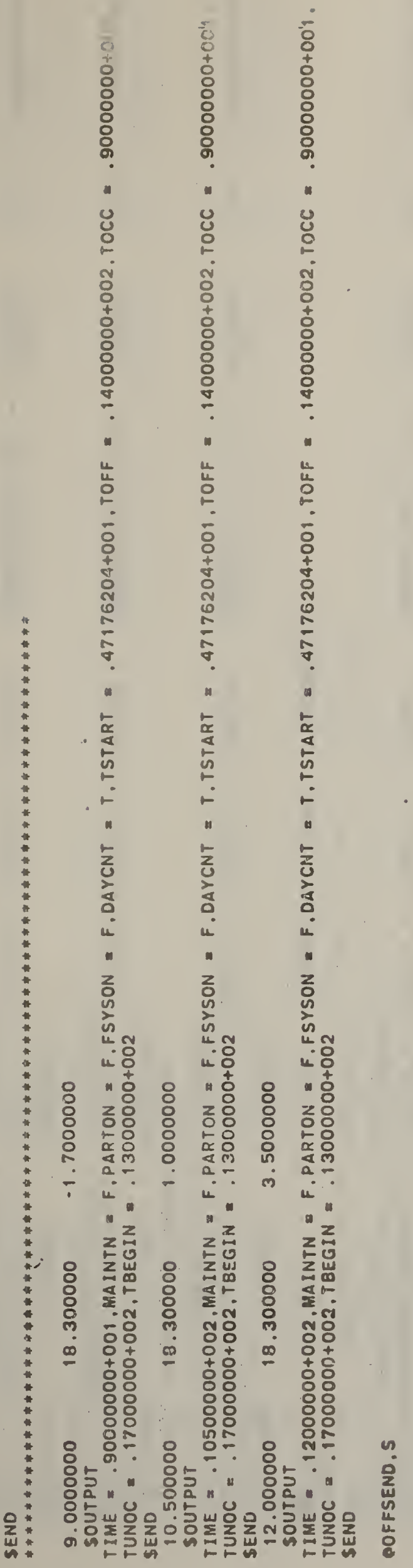




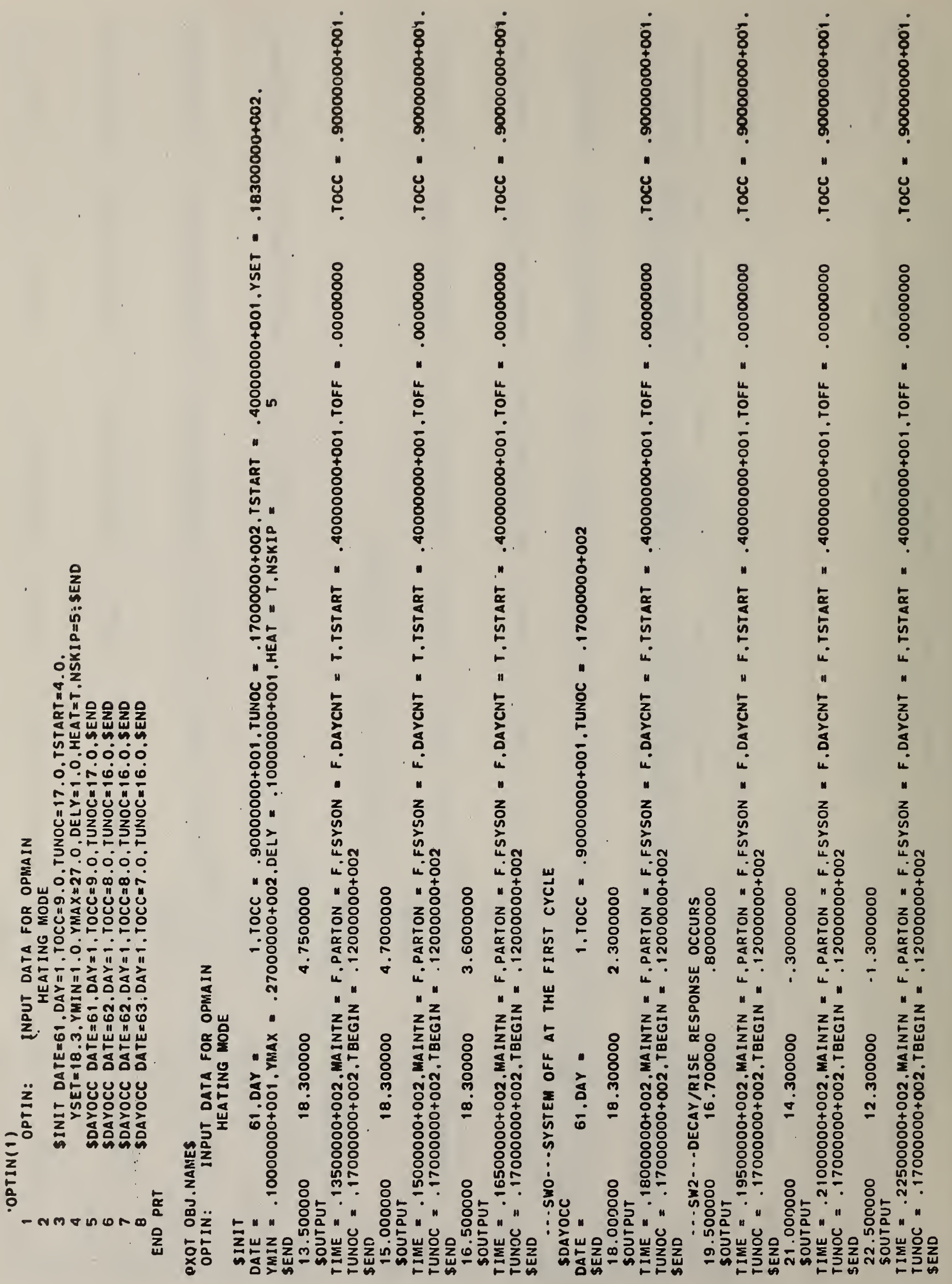




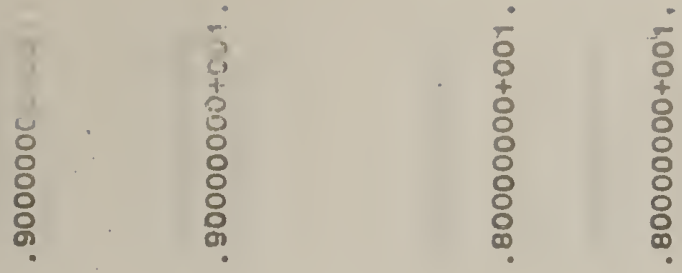

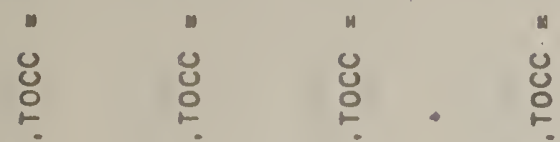

$\ddot{\circ}$
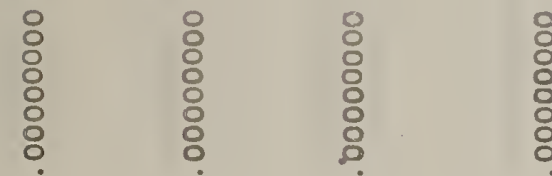

:
$\vdots$
$\vdots$
$\vdots$
$\vdots$
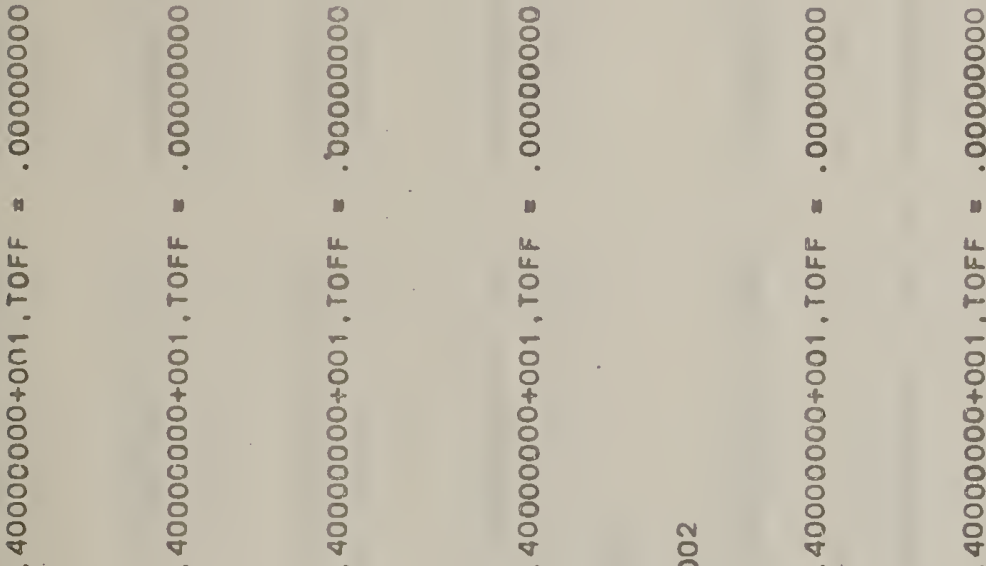

1
4
0
-
0
0
0
0
0
0
0
0
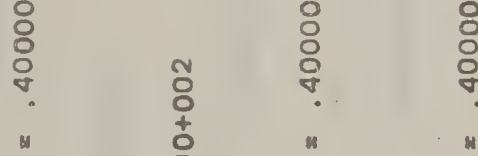

豪

兑

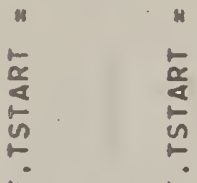

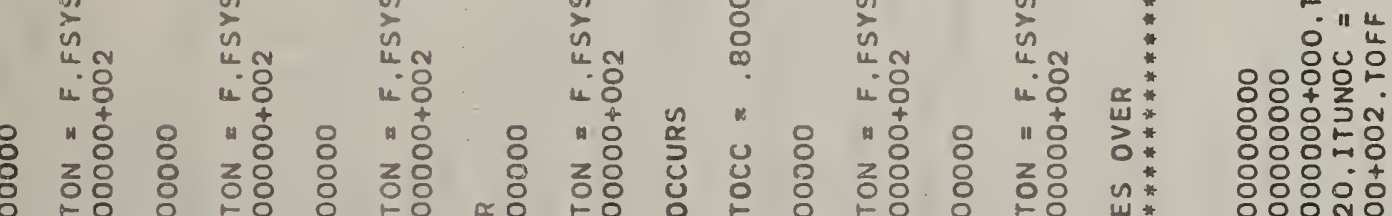

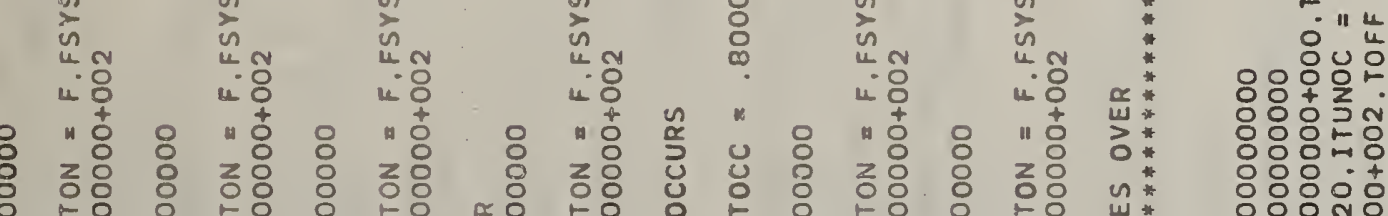

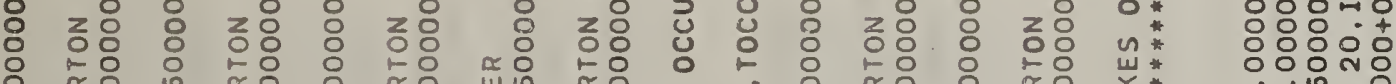

운

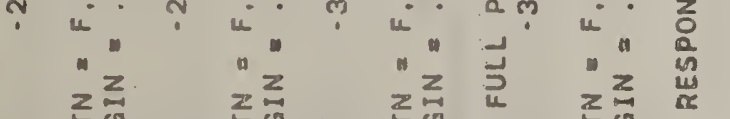

(1)

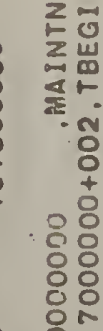

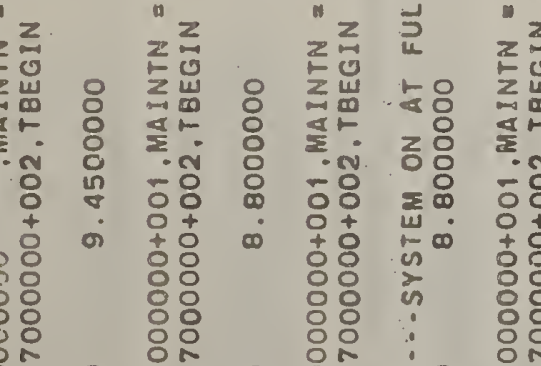

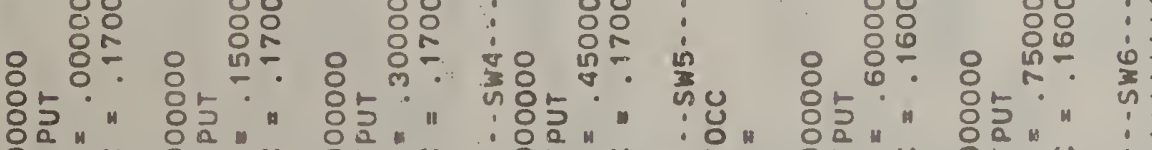

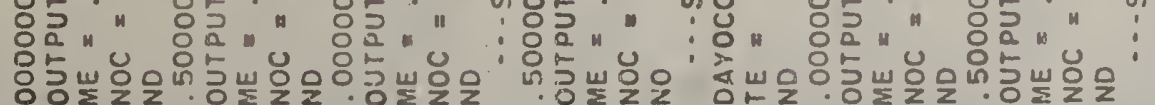

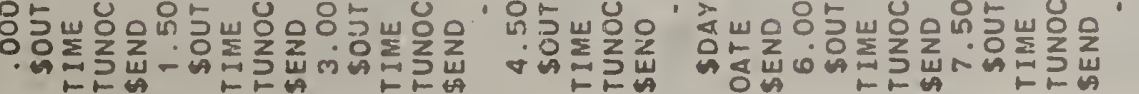
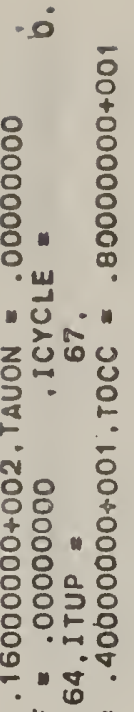

"

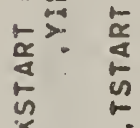

ㅇํㅁ "

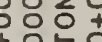
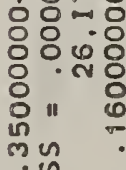

in 11

แัँे

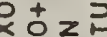

ํํㅇㅇํㅇ유융

+on

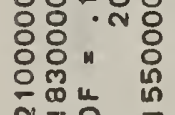

กั.ㄴํㅇ

…맘"

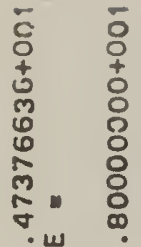

ผ $\vec{U}$.

zỡ

a-

ํํㅇํㅇ

항ㅇㅇㅇ

응응

앙나잉

$\because \square$

" $\frac{u}{2}$ "

䍃

5ㅇํㅇ 는

-8 n

응응ㅇ

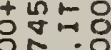

8 กิ่อ

ำ.

낸

ก.

능 "울

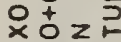

ㅅํㅇํำ

응응ํㅇ

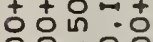

응응ㅇㅇㅇ

있. 임

ำำ ำ

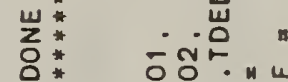

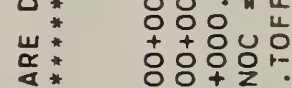

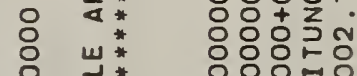

u* ․

ㄴ.

* * . 贤

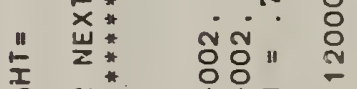

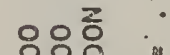

응ㄹ "

ㅇํㅇ는

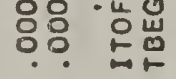

- 㽞

용유

응용

ㄷㅇㅇㅇㅡ." "

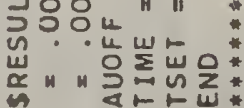

แ
항ㅎㅇㅇㅁㅇ

응ㅁㅆ "

융ㅇㅇㅇㄴ는

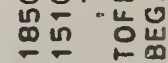

(0) 3 .

ㅅํㅇํㅇำ

운응

응응

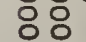

־유음" "

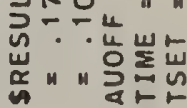

กู่ันกั 

a.

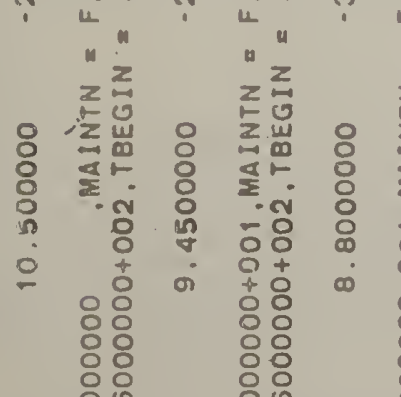
"J

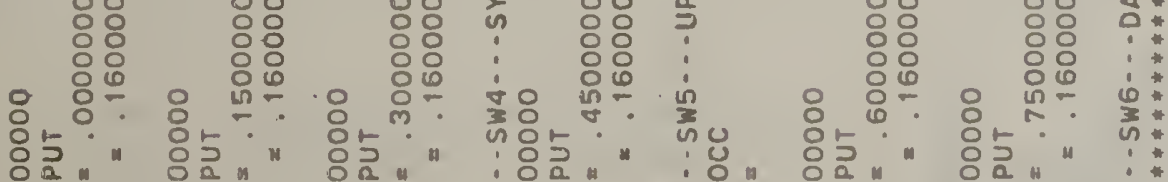

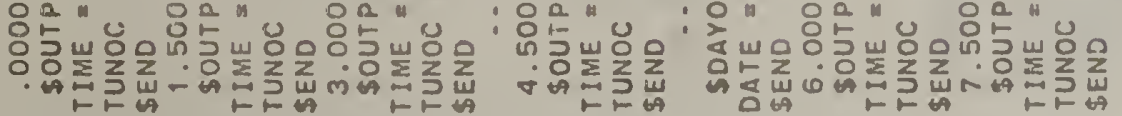

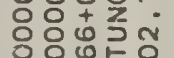

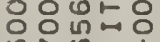

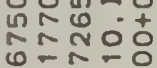

$0,-\frac{1}{2}-8$ ภำ ㅇํㅇ 만? 亭宫硈" 응응ㄴㄴㄴㅡ 约宊出
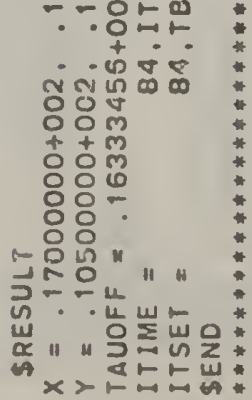


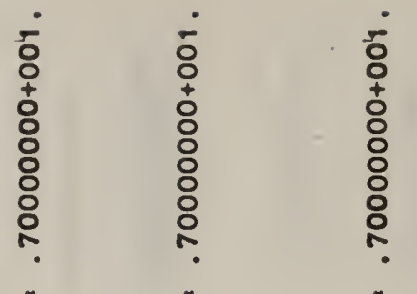

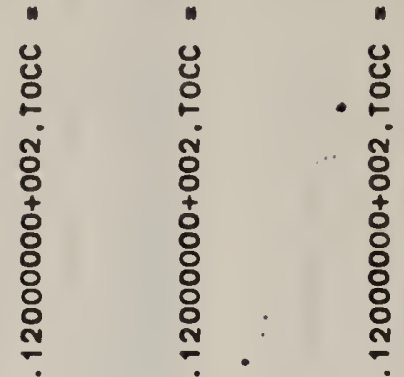

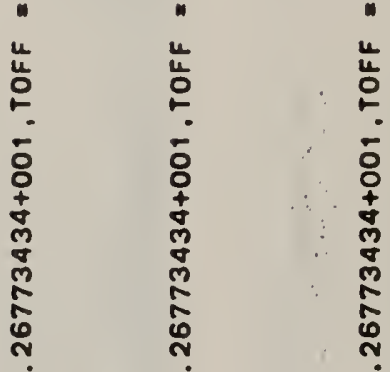

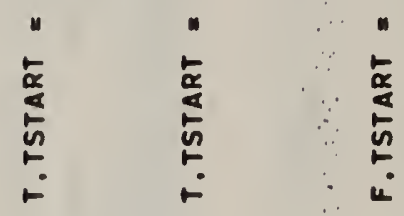

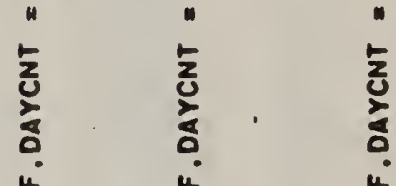

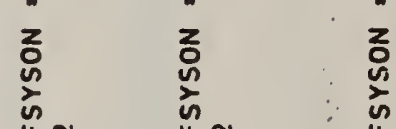

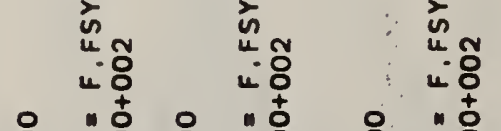

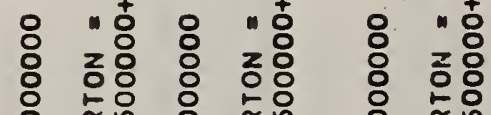

․ํํำ

" " " " "

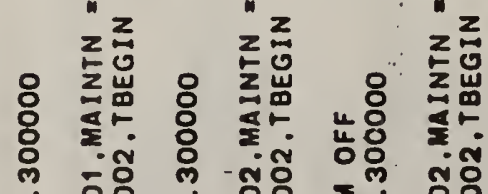

๓

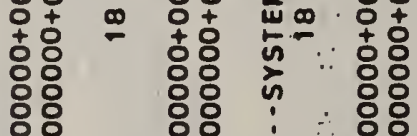

응 융 융유

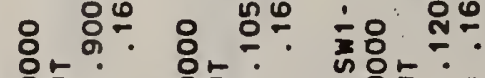

85."

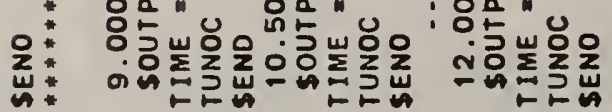

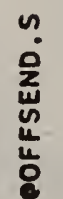


NES-114A (REY. 2-80)

U.S. OEPT. OF COMM.

1. PUBLICATION OR REPORT NO.

BIBLIOGRAPHIC DATA

83-2720

2. Performlng Organ. Report Nof 3. Publleatlon Date

SHEET (See Instructions)

4. TITLE AND SUBTITLE

An Optimum Start/Stop Control Algorithm for Heating and Cooling

Systems in Buildings

5. $\operatorname{AUTHOR}(\mathrm{S})$

Cheol Park

6. PERFORMING ORGANIZATION (If joint or other than NBS, see instructions)

7. Contract/Grant No.

NATIONAL BUREAU OF STANDARDS

DEPARTMENT OF COMMERCE

WASHINGTON, D.C. 20234

8. Type of Report \& Period Covered

9. SPONSORING ORGANIZATION NAME AND COMPLETE ADDRESS (Street, City, State, ZIP)

Office of Buildings and Community Systems U.S. Navy Civil Engineering Laboratory

U.S. Department of Energy

1000 Independence Avenue, SW

U.S. Department of Defense

Washington, DC 20585

10. SUPPLEMENTARY NOTES

[Document describes a computer program; SF-185, FIPS Software Summary, is attached.

11. ABSTRACT (A 200-word or less factual summary of most significant information. If document includes a significant bibliography or literature survey, mention it here)

When a building structure is occupied intermittently, energy savings can be realized from the optimal start-up and shut-down of the heating or cooling system. This strategy, known as optimum start/stop control, reduces energy consumption by delaying the start-up of the space conditioning system until the last moment and then initiating shut-down as early as possible, while maintaining a preset level of comfort during the period of building occupancy.

Based on the bang-bang control theory, a simple optimum start/stop control algorithm is developed for computerized control systems in buildings. The optimum start time is obtained by finding the intersection of cool-down and heat-up curves that are approximated by exponential fitting of the previous and current day's data.

Information is presented in this report on the input and output variables, logic flow, and methodology employed in developing the algorithm. A computer program listing of the optimum start/stop control algorithm written in FORTRAN 77 and sample input and output data are included in the appendices.

12. KEY WORDS (Six to twelve entries; alphabetical order; copitolize only proper names; and separate key words by semicolons) digital control systems; energy conservation; energy management and control systems; heating and cooling systems; optimum start/stop time; preheat time.

13. AVAILABILITY

X Unlimited

$\square$ For Official Distribution. Do Not Release to NTIS

$\square$ Order From Superintendent of Documents, U.S. Government Printing Office, Washington, D.C. 20402.

[X] Order From National Technlcal Information Servlce (NTIS), SprIngfleld, VA. 22I6I
14. NO. OF

PRINTED PAGES

69

15. Price 


